\title{
Sustainability nudges in the context of customer co-design for consumer electronics
}

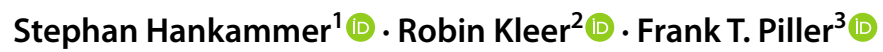

Accepted: 15 October 2020 / Published online: 18 November 2020

(C) The Author(s) 2020

\begin{abstract}
In this study, we shed light on the unexplored potential of customer co-design in a mass customization (MC) setting to contribute to the promotion of sustainable consumption. We theoretically derive and empirically test several opportunities for companies to improve sustainable consumption and production in a joint effort with consumers. Our research bridges between the $\mathrm{MC}$ and the sustainability literature and shows that MC enables consumers to cohere attitude and action, based on individual sustainability preferences. We empirically assess whether MC companies can nudge their customers successfully towards more sustainable choices by designing sustainability-based starting solutions (Study 1) and by providing transparent sustainability information (Study 2) in MC configuration systems. We do so by portraying a simulated online buying process of a customizable TV with a realistic web-based product configurator. We find that sustainable defaults can play a significant role in promoting sustainable consumption, while providing detailed sustainability information does not show an effect. To get more insights into our results, we discuss the results on a supplementary qualitative analysis based on think-aloud consumer tests (Study 3), revealing several suggestions for further research. Using these findings, we revisit sustainability information in Study 4 and find that intuitive labels significantly influence consumers to choose more sustainably.
\end{abstract}

Keywords Mass customization · Sustainability · Customer co-design · Consumer choice $\cdot$ Nudging $\cdot$ Product configurator

JEL Classification M14 · M39 - Q01 · Q59

Stephan Hankammer

stephan.hankammer@alanus.edu

1 Alanus University of Arts and Social Sciences, Villestr. 3, 53347 Alfter, Germany

2 Vlerick Business School, Reep 1, 9000 Ghent, Belgium

3 RWTH Aachen University, Templergraben 55, 52062 Aachen, Germany 


\section{Introduction}

Progress in production and information technology goes along with great possibilities for personalized production meeting individual consumer needs (Bughin et al. 2013). The aim of mass customization (MC) business models is to offer such customized products at near mass production efficiency (Pine 1993). The interaction between the MC company and its customers, the co-design process in which consumers customize the product according to their individual needs, is an essential factor in marketing mass customized products effectively (Salvador et al. 2009). For consumers, this phase is especially important as they determine the preference fit of the self-designed product (Franke et al. 2010). Digital choice navigation systems (i.e. product configurators) enable consumers in this phase to navigate effectively and efficiently through the co-design process. Research on the design of such "toolkits for customer co-design" (Franke and Piller 2003) provides recommendations on the general structure and order (Levin et al. 2002; Randall et al. 2005; Levav et al. 2010), price presentation (Park et al. 2000; Jin et al. 2012), default settings (Goldstein et al. 2008; Johnson et al. 2012), recommendations and peer-results (Franke et al. 2008; Hildebrand et al. 2013).

One important consumer trend, however, is only partially considered in research on customer co-design toolkits so far, notwithstanding its importance for society and businesses: sustainable consumption. In a world with finite resources, advancing climate change and increasing loss of biodiversity (Rockström et al. 2009; Lorek and Spangenberg 2014), influencing consumer behavior effectively towards sustainability is a key priority to ensure sustainable development (Fischer et al. 2017). Due to a rising awareness of negative environmental and social effects of production and consumption, sustainability considerations become increasingly important for both consumers and companies (see e.g., Rhein and Schmid (2020) for plastic packaging, Rex and Baumann (2007) for eco-labeling and Auger et al. (2010) for various social product attributes). Earlier research has demonstrated a positive effect of educating consumers how their consumption choices affect sustainability. Providing information regarding matters of sustainability can have positive effects on the purchase probability, willingness to pay and satisfaction after purchase (Sammer and Wüstenhagen 2006; Auger et al. 2008; Meise et al. 2014).

The co-design phase of MC is predestined for an analysis of promoting sustainable consumption: co-design requires active information exchange with the consumer (Salvador et al. 2009), and, thus, enables manifold possibilities to help consumers make better decisions for themselves, the society, and the environment. The objective of this study is to assess how to design this information exchange in order to nudge consumers towards more sustainable choices, using the carbon footprint as an example. Thereby, we aim to systematically integrate behavioral insights regarding sustainable consumption into the domain of MC research. Methodologically, we rely on consumer choice experiments (Alriksson and Öberg 2008). We present the results of two consumer choice experiments with a realistic product configurator for TVs, embedded in an online-survey, 
followed by a third, qualitative study to revisit the results of the two experiments, and a final choice experiment reconsidering and advancing one of the previous experiments in a modified manner.

Our study contributes to a better understanding of opportunities for companies to successfully influence consumer behavior towards sustainability. Our experiments show the existence of a positive effect of MC on sustainable consumption: MC enables consumers to cohere individual sustainability preferences with actual choice. Additionally, sustainable default settings and provision of sustainability information in an easy-to-understand manner can nudge consumers towards more sustainable choices. Our results complement the existing research on consumer choice navigation tools and provide recommendations for a suitable configurator design for more sustainable customizable products.

\section{Background and hypotheses}

\subsection{Sustainable consumption, pro-environmental behavior, and green nudging}

Since the United Nations Conference on Environment and Development (UNCED) was held in Rio de Janeiro in 1992, how to reach sustainability through sustainable production and consumption has been an integral component of the discussion about sustainable development. The UNCED demanded the industry to lower their environmental impact (UNCED 1992). However, not only producers are held responsible for moving towards sustainability, also consumer behavior plays a critical role (O'Rourke and Ringer 2015). Two years later, the term 'sustainable consumption' was formally introduced by the Oslo Symposium on Sustainable Consumption in 1994 and has, since then, received growing attention in academia and public media (Fuchs and Lorek 2005; Liu et al. 2017). Sustainable consumption is defined as "the use of services and related products which respond to basic needs and bring a better quality of life, while minimizing the use of natural resources and toxic materials as well as emissions of waste and pollutants over the life cycle of the service or product so as not to jeopardize the needs of future generations" (Ofstad et al. 1994).

Within the overall discourse on sustainable development, sustainable consumption is considered as a key pillar to integrate sustainability into every-day practices (Mont 2004). The urgency to study ways to engage sustainable consumption increases (Wang et al. 2014). This is especially the case because consumption behavior has shifted away from the paradigm of satisfying daily needs towards a paradigm that regards consumption as a tool for self-realization and self-identification (Firat 1991; Honneth 2004). Today, the majority of consumers admit to apprehend the environmental impact of their own consumption (Kalamas et al. 2014). However, the relationship between pro-environmental attitudes and outcomes is often not coherent (Kollmuss and Agyeman 2002; Jacobs et al. 2018). Consumers have difficulties to act according to their attitude (Schäufele and Hamm 2018; Farjam et al. 2019) and to adopt sustainable consumption practices such as accepting sharing and circular business models (Hankammer et al. 2019; Elzinga et al. 2020). To study 
how sustainable consumption can be achieved, we, thus, need to look at the individual decision-making process of consumers.

A possible way to encourage people to act in a pro-environmental manner is to use so called 'green nudges' (Schubert 2017). Nudges are defined as "any aspect of the choice architecture that alters people's behavior in a predictable way without forbidding any options or significantly changing their economic incentives" (Thaler and Sunstein 2008, p. 6). This definition underlines that nudges do not restrict any actions, but rather guide people's actions with the help of the architecture of choices. For green nudges, three main types of nudges are described: (1) simplifying product information or making certain product characteristics more salient to activate green behavior, (2) integrating peer comparisons or status competitions, and (3) exploit passive choice with purposefully set defaults (Schubert 2017).

A business model in which the architecture of choices plays a particular important role is MC, as MC requires an efficient process of navigating consumers to their perfect individual preference fit.

\subsection{Mass customization and product configurators}

MC is the ability to provide individually designed products and services to every customer through high process agility, flexibility and integration (Davis 1987). Hence, the very basic idea of MC is to provide goods and services that coincide with the idiosyncratic needs of customers, while maintaining mass production efficiency (Tseng and Du 1998). Salvador et al. (2009) emphasize the need for three management capabilities for successfully offering MC products: robust process design, solution space development and choice navigation. Robust process design refers to fulfilling differentiated customer needs through efficient use of organizational and value chain resources (Salvador et al. 2009). Solution space development refers to finding the right extent of customization to meet customer demands, while ensuring that every customized product is producible effectively (Piller and Tseng 2010; Grafmüller et al. 2018). Choice navigation refers to marketing MC products effectively and thus focuses on the interaction between the company and its customers: the co-design process in which customers design the product according to their individual needs (Salvador et al. 2009). A core element that ensures customers can be navigated effectively and efficiently through the co-design process is a digital choice navigation system (Forza and Salvador 2006). With modern communication technologies, web-based configurators have become the most convenient user toolkit to manage the interaction with the individual customer (Piller et al. 2004; Piller and Walcher 2006). Such toolkits provide MC companies with the "ability to obtain precise information on what customers actually want" (Franke et al. 2009, p. 103) and directly translate consumer preferences into valid technical specifications (Gembarski and Lachmayer 2017). Vice versa product configurators also entail a "process of learning about the available attributes and alternatives" (Huffman and Kahn 1998, p. 492). For customers, the co-design process enables "trial-and-error learning with an immediate feedback function" (Franke and Piller 2004, p. 405). Customers can 
learn their preferences iteratively until all information about fit, style and functionality (Piller 2004) and other relevant information such as price, function, and the optimum product design are transferred (von Hippel and Katz 2002).

\subsection{Prior research on sustainable consumption in a mass customization context}

The two research fields of sustainable consumption and MC have not been studied together intensively yet. The analysis of the social and environmental perspective of customization is still a niche topic (Hankammer et al. 2020). However, recently, several contributions called for further research in this category (Kohtala 2015; Hora et al. 2016), leading to special tracks and corresponding publications at international conferences such as the 9th World Mass Customization Conference 2017, which put special emphasis on discussing" how Customization 4.0 fosters sustainable development" (Hankammer et al. 2018b, p. v). The majority of existing studies are conceptual pointing out theoretically derived potentials of MC for contributing positively to sustainability (Osorio et al. 2014; Pourabdollahian et al. 2014; Gembarski et al. 2018). For instance, Pourabdollahian et al. (2014) indicate several impact factors of MC on sustainability at all stages of the product life cycle.

In the slowly sprouting research on sustainable MC, co-design is frequently mentioned to entail several environmental potentials. Hansen et al. (2009) claim that MC could gain significant importance in the course of sustainability in the future, because companies can gain useful insights from consumers in the co-design phase. Vice versa, Badurdeen and Liyanage (2011), Kohtala (2015) and Hankammer et al. (2018a) indicate the potential of customer co-design to create awareness of consumers and promote more sustainable consumer choices. The inertia of co-design interaction between MC companies and consumers "opens a platform for sustainable value co-creation" (Badurdeen and Liyanage 2011, p. 200). This also corresponds to sustainable consumption research perception that active consumer involvement is a key component of sustainable consumption (Lorek and Spangenberg 2014). According to Hankammer and Kleer (2018) turning consumers into prosumers (i.e. people who both consume and produce (Kotler 1986)) could support the transition to sustainable consumption. Following this logic, the active involvement of consumers in MC of goods could transfer their social motivation into more conscious consumption practice (Klintmann 2012). The main aim of our study is to fill the gap of no empirical research yet proving the potential of product configurators to create awareness and promote more sustainable choices.

\subsection{Hypotheses development}

For the research field of sustainable consumption, the analysis of MC as a business practice and customizable products and services as the unit of analysis constitute a particularly interesting perspective. Our article follows the rationale that MC could be used as a vehicle to enable sustainable consumption per se. The main reason for this assumption is that people's heterogeneity in their preferences (Piller 2004) could also include their individual consciousness for sustainable consumption (CfSC). The 
degree people care about the environment and are disposed to invest in less impacting products and services differs (Balderjahn et al. 2013). Thus, the very basic idea of MC to produce goods and services that closely fit consumers' individual needs makes MC especially suitable to address consumers in their heterogeneous attitude towards sustainability. While niche groups (e.g., people with a very high CfSC) are often not covered by mass markets, MC offerings with decomposed choices among manifold characteristics of a product or a service could cohere attitude and actions.

Hypothesis 1 (H1): MC enables consumers to transfer their individual CfSC into coherent action.

The next hypotheses try to verify the sustainable default effect. We claim that the co-design phase of MC could be designed to encourage pro-environmental behavior: choice architects can vary the number of most and least sustainable pre-configured choices (green nudge type 3). A default is defined as option a consumer gets if not explicitly requested otherwise (Brown and Krishna 2004). Many studies have shown that the probability of choosing a specific option increases if this option is set as default (e.g., Johnson et al. 2002; Johnson and Goldstein 2003; Haward et al. 2012). Customizing a product using a configuration tool can be a highly complex task, which requires considerable effort by the user (Huffman and Kahn 1998). MC companies set default options to reduce the perceived complexity of the customization process and increase the utility of the configurator (Dellaert and Stremersch 2005). Consumers often lack the required know-how to transfer their preferences into a product configuration (Franke and Hader 2014), and thus, defaults are often perceived as helpful implicit recommendations of apparent experts (Schubert 2017). We claim that similarly to the functioning of defaults in standard configurators, sustainability defaults significantly affect consumer behavior in a pro-environmental direction.

Hypothesis 2a (H2a): MC companies can nudge consumers towards more sustainable choices by designing more environmentally-friendly starting solutions.

If the sustainable default effect is confirmed, choice architects have an effective instrument at hand to foster sustainable consumption. However, according to Thaler and Sunstein (2008) a nudge promotes, and does not undermine, people's welfare. Thus, companies should only use such choice architectures in practice if consumer satisfaction is not affected negatively. Companies need to make sure that green nudges do not result in lower levels of consumer satisfaction, or else it would result in consumer deception (Thaler and Sunstein 2003). The endowment effect is an argument against this condition. The effect describes "that losses loom larger than gains" (Levin et al. 2002, p. 336). According to Kahneman et al. (1990), if you own a particular item, the incremental value of losing it is greater than the value you would feel if you gained it. While a pre-configuration is not like owning a product literally, it works as a determining frame for the user of the product configurator. Transferred to the context of sustainable defaults the endowment effect predicates that the loss of satisfaction due to reducing the environmental performance 
of a product compared to the gain in another category (e.g., functionality), is relatively stronger when departing from a sustainable starting solution. However, in the context of product configurators, we do not have only one or two-dimensional, but multi-dimensional trades (price, functionality, fit, esthetics, etc.). Therefore, it is difficult to predict which categories dominate consumers perceived loss aversion. We hypothesize that environmental default settings do not undermine people's welfare and thus do not have a negative impact on consumers' appraisal of the outcome of the customization process.

Hypothesis 2b (H2b): Environmentally-friendly starting solutions do not negatively affect consumer satisfaction.

Nudging consumers towards more sustainable choices with the help of default settings stipulates "what happens if people don't actively choose" (Schubert 2017, p. 331) (green nudge type 3). A different way to stipulate more sustainable choices is to highlight the environmental impact of these choices, i.e. a nudge that makes "certain product characteristics more salient" (Schubert 2017, p. 331) (green nudge type 1). The importance of enhanced product information for sustainable consumption has been repeatedly highlighted (Dendler 2014). Research has shown that providing information regarding matters of sustainability can have positive effects on the purchase probability as well as the willingness to pay, and the satisfaction after purchase (Auger et al. 2003; Sammer and Wüstenhagen 2006; Alriksson and Öberg 2008; Meise et al. 2014). In general, product information plays a vital role in informing consumers about the characteristics of a product and thus enabling a deliberate purchase decision. Take the example of TVs; consumers seek information about size, type, color, functions, but also about price and energy consumption. Consumers' ability to identify choices with higher or lower environmental impact depends on their sustainability knowledge or the ad-hoc information provided in the buying process. A lack of information about product sustainability is a barrier preventing consumers from choosing more environmentally-friendly products (Cerri et al. 2018). The direct provision of sustainability information reduces search costs and eases the evaluation of the different alternatives (Maity and Dass 2014; Meise et al. 2014). We therefore assume that MC companies highlighting the environmental impact of consumer choices in the sub-steps of the customization process can influence the likelihood of consumers to opt for more sustainable options.

Hypothesis 3 (H3): MC Companies can nudge consumers towards more sustainable choices by highlighting sustainability information in configurators.

\section{Research design}

\subsection{Research setting}

Particularly in developed countries, household consumption contributes most to greenhouse gas emissions (Hertwich 2005). Within household consumption, the 
purchase and use of consumer electronics goods are especially suitable to analyze sustainable consumption. The consumer electronics industry is generally resourceintensive, still uses hazardous materials, has high transportation emissions and uses energy covered predominantly by coal-fired power stations due to off-shore production (mainly in Asian countries) (Cobbing and Dowdall 2014). Recently more electronic devices comply with stricter energy consumption regulations due to legislation but also due to higher consumer attention to this topic (Sammer and Wüstenhagen 2006). Hence, consumers are widely familiar with initiatives to increase the environmental sustainability of goods in this sector. However, the lifespan of consumer electronic goods become shorter due to the fast progression in technological advancement and rapidly sinking prices of electronics (Kalana 2010; Zufall et al. 2019). Consumers buy new electronic devices more frequently and hence the amount of electronic waste constantly increases from 34 million tons in 2012 to estimated 50 million tons worldwide in 2018 (Sthiannopkao and Hung 2013).

Due to the special relevance of consumer electronics for studying sustainable consumption, we developed and used an MC configurator for television sets (TVs) as a unit of analysis for testing our hypotheses. Several characteristics of TVs particularly serve the purpose of our study: TVs are usually rather difficult to assess for consumers in terms of sustainability, TVs are composed of manifold hardware, software and service features, and some of the components have significantly high carbon footprints. Moreover, we selected the example of TVs, exploiting opportunities to collaborate with a large European manufacturer of TVs and use realistic product, production and pricing data. In Study 1, we focused on the impact of defaults on carbon footprints of customized products, while Study 2 focused on the provision of sustainability information. In Study 3, we revisited our results (especially of Study 2) with a qualitative analysis. Study 4 builds on the insights derived in Study 3 and reconsiders the provision and visualization of sustainability information in a modified manner.

\subsection{Experimental design}

Together with a large European manufacturer of TVs and a European research consortium consisting of experts in the field of environmental sustainability, supply chain management, industrial design, and MC, we developed and prepared an MC product offering that enabled participants to customize a TV in six different areas (screen, frame and stands, hardware, software, service, packaging and delivery), 19 different customization categories (e.g., screen size, frame material, take-back service) with 2-5 different options (e.g., 49 inch or 55 inch) resulting in 8,847,360 possible different TV combinations. The entire solution space is depicted in Table 1.

Preceding this study, we evaluated the greenhouse gas emissions within the different phases of the product lifecycle based on lifecycle assessment (LCA) data for each option of the solution space measured in $\mathrm{CO}_{2}$ equivalents $\left(\mathrm{CO}_{2} \mathrm{e}\right)$. Also, the prices for the options were estimated based on realistic data (cost or estimated market price) provided by the TV manufacturer. 


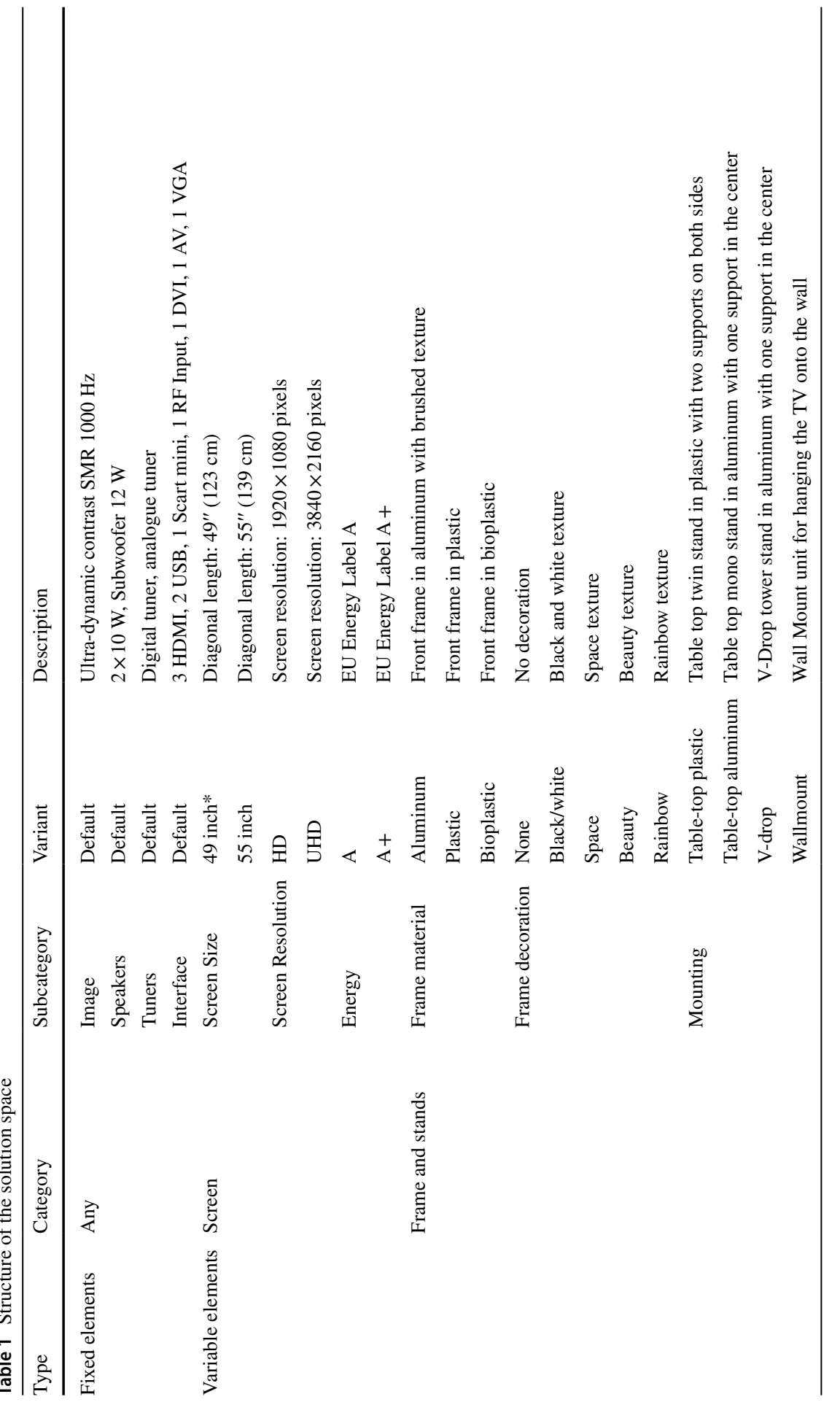




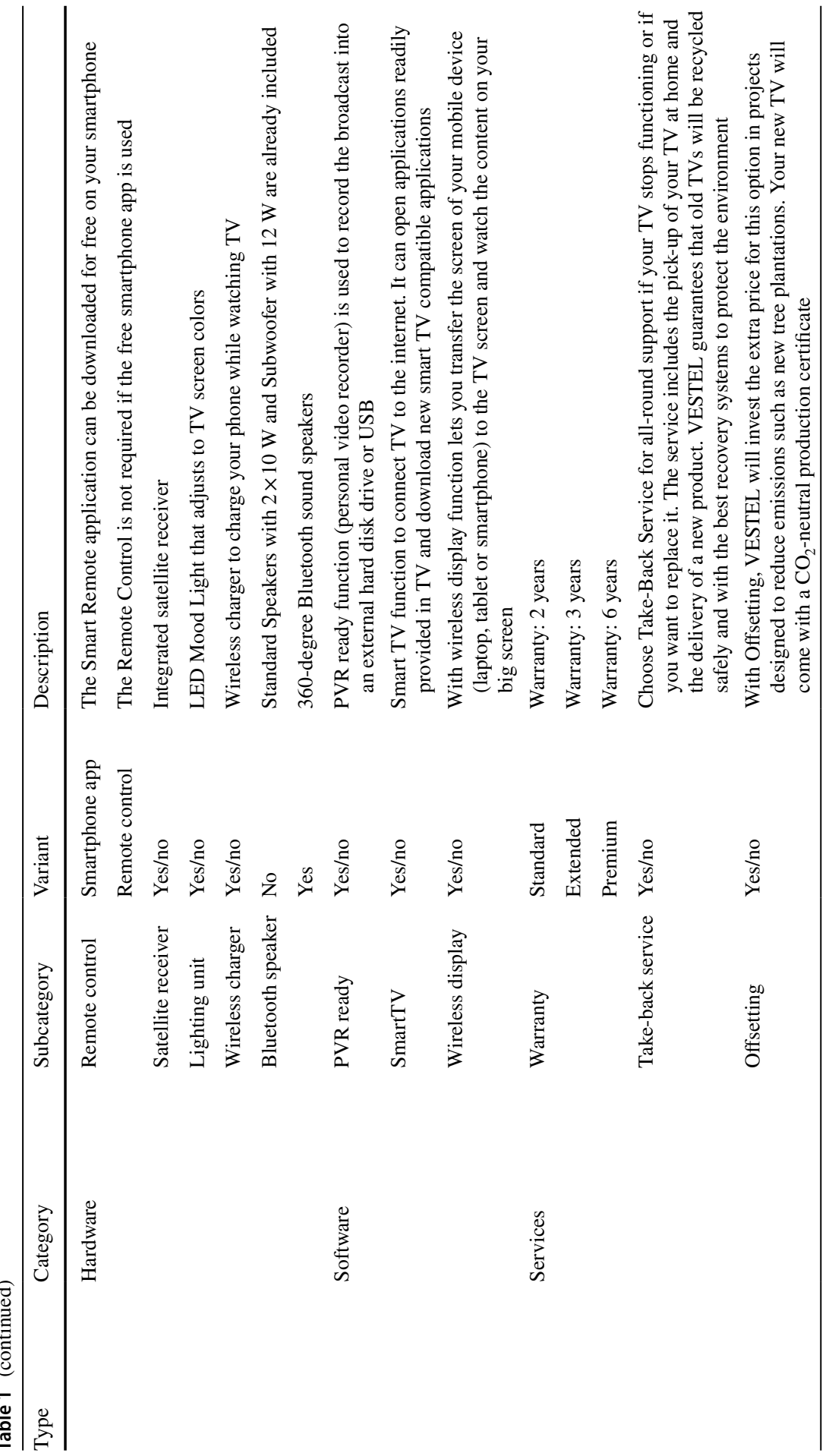




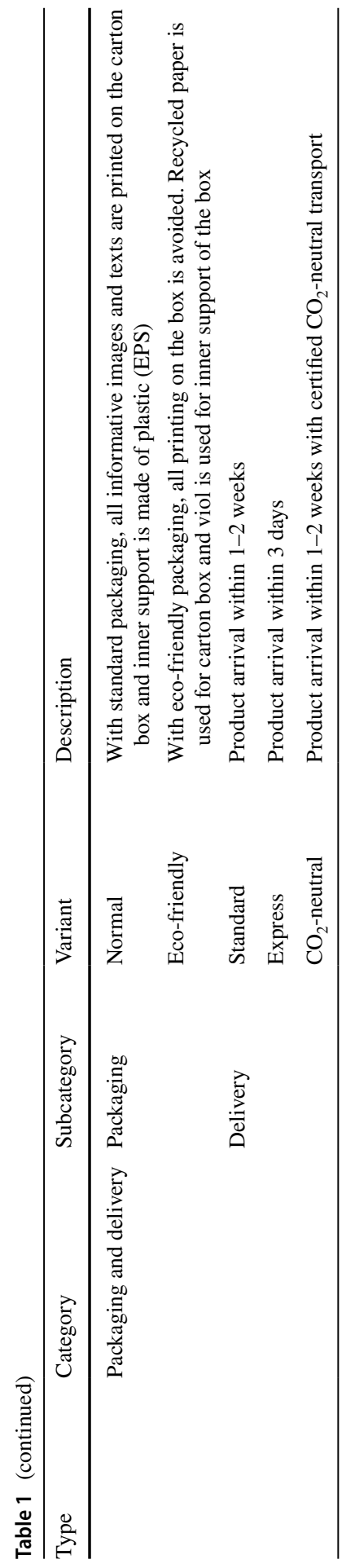




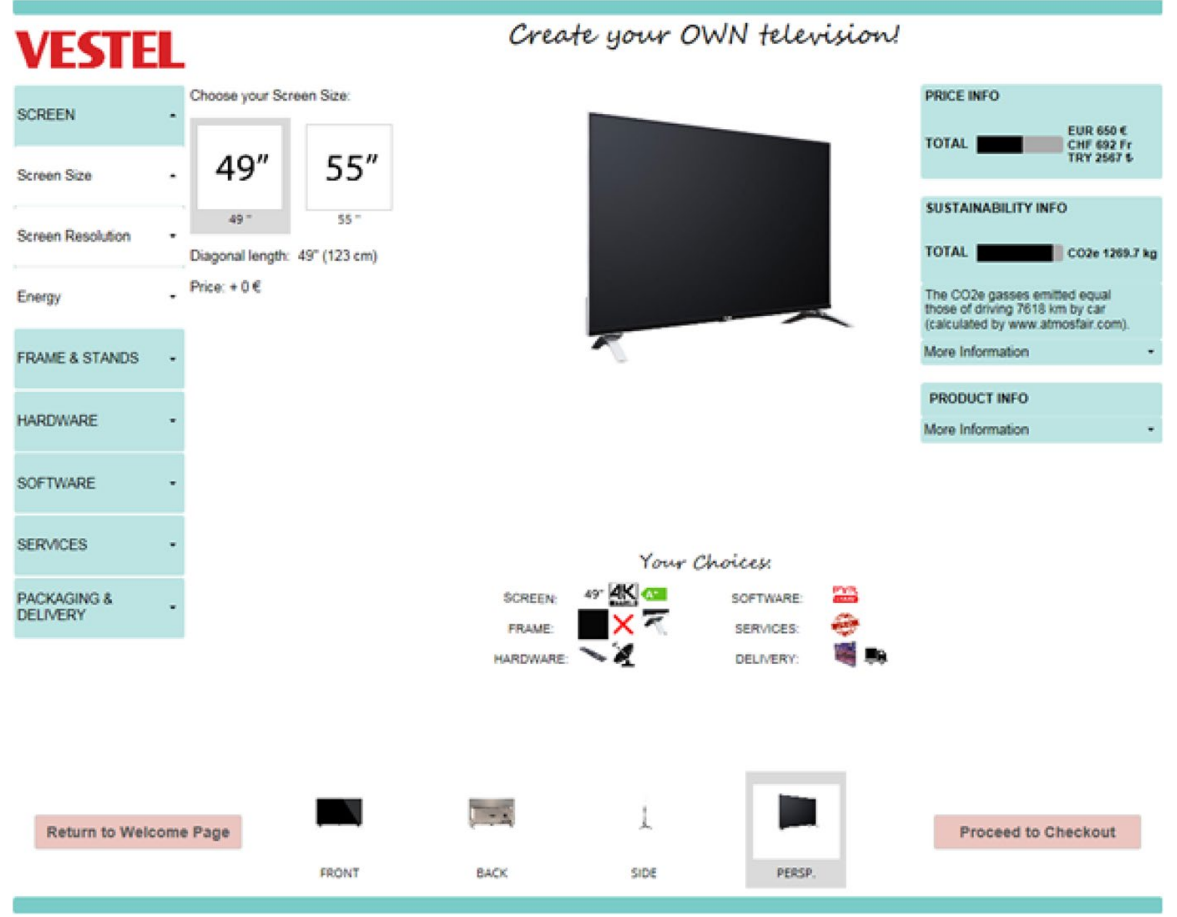

Fig. 1 Web-based product configurator for TVs

The product configurator was designed to mimic the interaction process between MC companies and their customers. Using the configurator software Combination, we computed a web-based product configurator with a starting page, a configuration page and a checkout page. The configuration page (Fig. 1) contained a navigation panel, component panel, visualization panel, and an overview panel. The participants could use the navigation panel on the left side to go through all 19 configuration steps. Using the navigation panel, the participants could jump forth or back to any step at any time. The component panel displays all choices the participants made in the selected configuration step. Below the thumbnail picture, the price premium of the selected component is displayed if it is not the cheapest option. In the visualization panel, the product image is displayed. This image adjusts to the participant's choices in Screen Size, Frame Decoration, and Stands \& Mounting. Below the product picture, the customer can see the thumbnail pictures of all selected choices. Further, at the bottom, the customer can change the view angle of the product.

Finally, in the overview panel at the right side, there are three info boxes for the price, the sustainability assessment, and the technical product overview. The price is displayed in the currencies of the countries where the configurator was tested. The sustainability info box displays the total carbon footprint of the product in $\mathrm{kg} \mathrm{CO}_{2} \mathrm{e}$. The bar ranges on a scale between 786.4 and $1454.8 \mathrm{~kg} \mathrm{CO}_{2} \mathrm{e}$, which equals the range of possible carbon footprints. In the sustainability info box customers can obtain more in-depth knowledge on the sustainability impact 
Table 2 Survey structure

\begin{tabular}{lll}
\hline No & Content & Part \\
\hline 1 & Introduction to the survey & Pre-configurator survey \\
2 & Dropout question & \\
3 & Demographics & \\
4 & Involvement with televisions & \\
5 & Consciousness for sustainable consumption & \\
7 & Experience with configurators & Configurator \\
8 & Instructions for configurator & \\
9 & Welcome page: default configuration & \\
10 & Configuration page: customization & Post-configurator survey \\
11 & Checkout page: product summary & \\
12 & Satisfaction with product and process & \\
13 & Feedback question & \\
14 & "Thank you" message & \\
\hline
\end{tabular}

within the different life cycle phases (extraction, production, transportation, use, and disposal) of the current configuration. Additionally, the range of driving by car that would generate an equal carbon footprint is displayed for the total $\mathrm{CO}_{2} \mathrm{e}$ value. The product info box contains the current product configuration (all components selected at present).

We embedded the web-based configurator for TVs in a questionnaire survey using the software unipark. The online survey consisted of demographic questions (age, gender, income, qualification, residence), questions to measure the starting conditions for customizing goods [experience with configurators (EwC) (adapted from Franke and Hader 2014), product involvement (PINV) (Zaichkowsky 1985), and consumer consciousness for environmentally friendly consumption as one core facet of sustainable consumption (Balderjahn et al. 2013)]. Moreover, after having conducted the consumer choice experiment, we asked participants to rate their confidence with their choice including process and product satisfaction, and their learning (see Table 2 for an overview of the structure of the survey). The research setting was Europe with a focus on Germany, Switzerland, Italy and Turkey in Studies 1 and 2, Germany in Study 3 and Belgium in Study 4. The language of the survey was English.

To measure the environmental impact of the customized TV (dependent variable), we used the carbon footprint of the final configuration calculated in $\mathrm{CO}_{2} \mathrm{e}$. To mitigate climate change, the reduction of greenhouse gas emissions, such as $\mathrm{CO}_{2}$, has become one of the most important measures (Sundarakani et al. 2010; Chen and Chen 2017). We measured CfSC with a seven point Likert scale with the eight items of the environmental dimension of CfSC suggested by Balderjahn et al. (2013). Also for measuring PINV (three items), EwC (four items, adapted from Franke and Hader (2014), product satisfaction (two items), process satisfaction (four items), we used 7-point Likert scales. Multi-item constructs were averaged (see Table 3 for an overview of all scales used for our analyses). 


\subsection{Pretest}

We conducted a pretest with 139 university students to test the underlying scales, the provision of sustainability information and the solution space of all options offered in the configuration process. We especially focused on testing the acceptance and comprehensibility of different ways to include and visualize sustainability information within a product configurator. We asked participants to rate three different alternatives. A traffic light switching between red, yellow and green, a bar that fills up the more emissions are set free in the selected configuration and a thumbs up or thumbs down visualization. After having evaluated each alternative separately, participants were asked to directly compare the three options. Table 4 sums up the results, resulting in the selection of sustainability bars as the preferred choice for the presenting the environmental impact of the configuration. In Study 2, we therefore opted for choosing a sustainability bar. The pre-test of the internal consistency of the underlying scales revealed high reliability with Cronbach's alphas between $\alpha=0.79$ and $\alpha=0.96$ (DeVellis 2012).

Before sending out the invitations to participate in the surveys, we carried out an additional pretest to check the consistency of our final survey and the usability of the configurator. A group of voluntary participants carried out the survey and afterwards stated what kind of starting solution they had and what kind of sustainability information they perceived in the experiment.

\section{Study 1: sustainable default test}

In the first study, we aimed to examine the effectiveness of designing starting solutions of configurators based on the environmental footprint of the default configuration. With this experiment, we tested Hypotheses 1, 2a and $2 \mathrm{~b}$ with a betweensubject design.

\subsection{Stimuli: manipulating the starting configuration default}

To test the role of default settings for influencing pro-environmental behavior, we developed three different starting scenarios for the configuration process. The first default treatment included the least sustainable option within each category (high sustainability impact). The second default setting was designed following the characteristics of the current bestseller of the TV manufacturer with a lower environmental impact compared to the first default (medium sustainability impact). The last default setting contained all the options with the lowest carbon footprint (low sustainability impact). One out of these three default configurations was assigned randomly to the respondents when entering the configurator. Table 5 summarizes the three starting solutions.

To ensure that the participants perceive the composition of the starting solution, we designed a welcome page, which shows the pre-configured TV. Upon entering the configurator, the participants found an overview of the product in its default configuration. They also immediately saw a product picture in the perspective view located in 


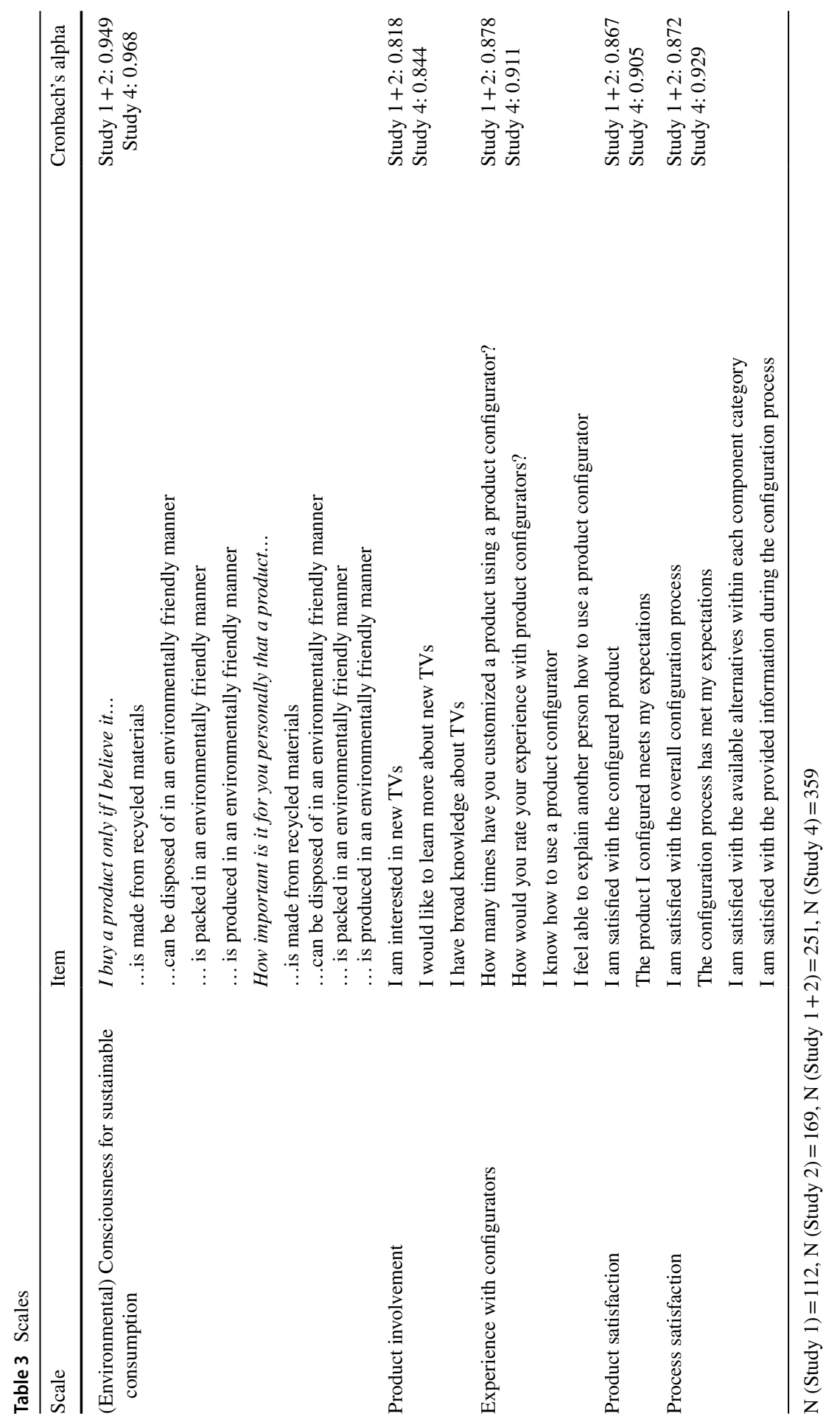


Table 4 Pretest for sustainability visualizations

\begin{tabular}{lllr}
\hline & Traffic light & Bar & Thumb \\
\hline Most informative & 17.89 & 65.85 & 8.13 \\
Most intuitive & 44.72 & 19.51 & 31.71 \\
Most reliable & 21.14 & 57.72 & 13.01 \\
Most appropriate & 28.46 & 47.97 & 19.51 \\
Favorite alternative & 26.83 & 49.59 & 20.33 \\
\hline
\end{tabular}

$\mathrm{N}=113$

the center. This gave them an instant idea of the product. On the right side, they found the price for the TV in its default configuration. Below the price, participants found information on the carbon footprint of the TV's initial configuration and the equivalent driving distance. At the bottom right corner, a red button "Start Configurator" took the customer to the configuration page. Participants could return to the welcome page at any time if they wanted to compare their own configuration to the default configuration.

\subsection{Participants and procedure}

Studies 1 and 2 were conducted in parallel using the same survey but embedding different configurator versions to test the hypotheses independently. We sent the survey to university students in Germany, Switzerland, Italy and Turkey, and published the link to the survey on the European research project website and social media channels. Thus, other than for our subsequent Study 4, we did not use a representative sample for Studies 1 and 2. 460 participants finished the survey. To increase the sample reliability, we conducted several plausibility checks. We included time measurements of participants taking the survey (total time in survey and time in configurator) and recorded and counted clicks within the different configurator panels during the configuration process. Moreover, we deleted participants with missing values in the core variables. As the results of statistical analysis can be sensitive to outliers, we calculated Cook's distance to eliminate the gross outliers for which Cook's distance exceeds 1 and excluded such observations from our analysis.

Following the data cleaning procedure described above, 112 respondents assigned to one of the three default scenarios remained. 86 respondents were male, 26 were female. The age ranged between 18 and 62 years with an average of 29 years. The median income of the sample was between 1500 EUR and 2000 EUR. Most participants lived in Germany (62) followed by Switzerland (26), Italy (10) and Turkey (6). Eight participants lived in other countries. The median qualification of the sample was bachelor's degree.

\subsection{Results}

Hypothesis 2 a stated that consumers can be encouraged to customize more sustainable products through the design of the starting solutions (defaults) of the configurator. We performed a manipulation check to test whether the design of defaults 


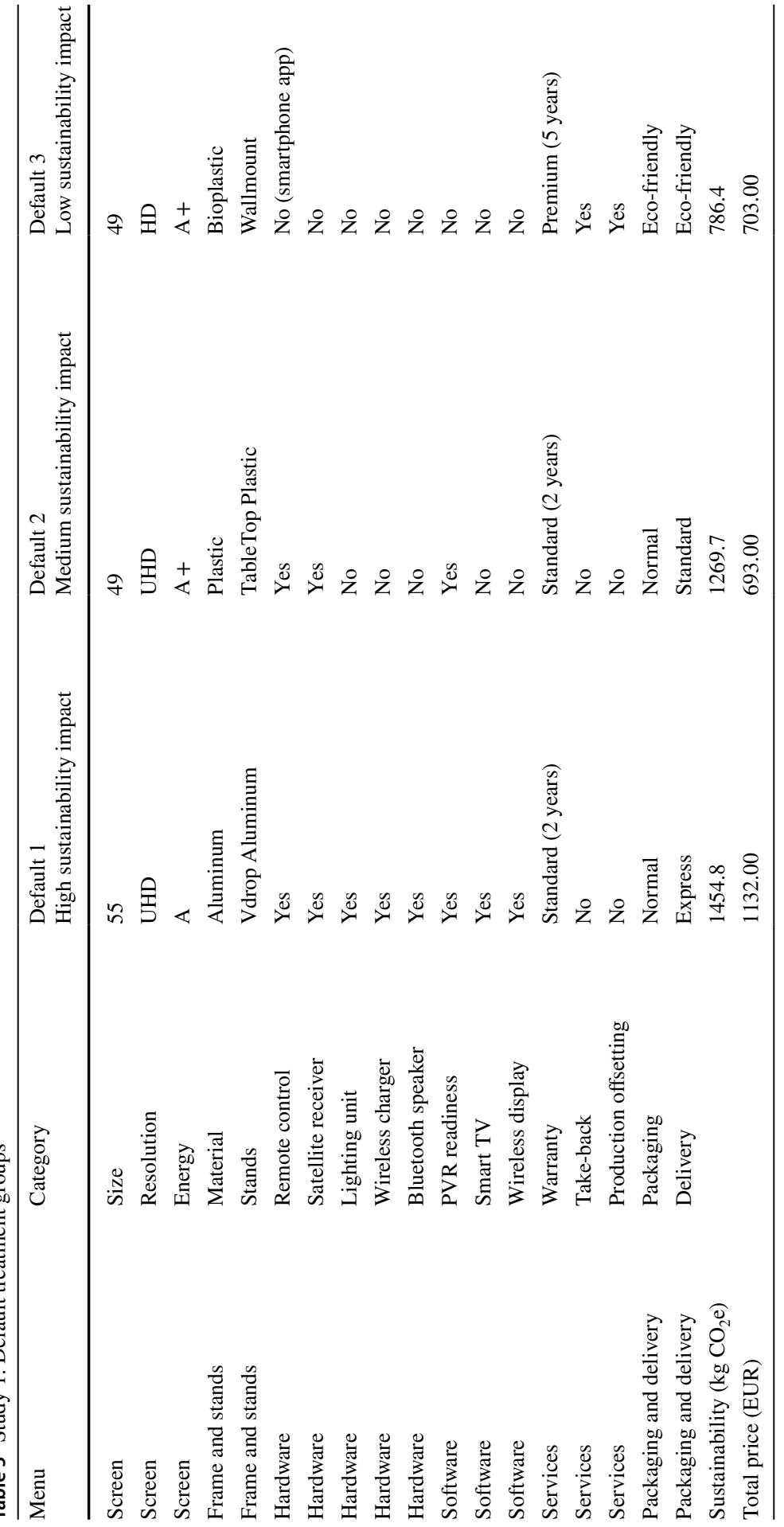


Table 6 Study 1. Post-hoc analysis of main effects of default treatments

\begin{tabular}{|c|c|c|c|c|}
\hline \multirow[t]{2}{*}{ Dependent variable } & \multirow[t]{2}{*}{ Post-hoc test } & \multicolumn{3}{|c|}{ Post-hoc analysis } \\
\hline & & $\begin{array}{l}\text { Treatment } 1 \\
\text { vs. } 2\end{array}$ & Treatment 1 vs. 3 & Treatment 2 vs. 3 \\
\hline Carbon footprint & Tukey HSD & n.s & $\mathrm{p}<0.001$ & $\mathrm{p}<0.05$ \\
\hline Product satisfaction $^{a}$ & Games-Howell & n.s & n.s & n.s \\
\hline Process satisfaction $^{a}$ & Games-Howell & n.s & n.s & n.s \\
\hline
\end{tabular}

aAssumption of homogeneity of variances violated (Levene's test)

was manipulated successfully. ANOVA revealed that the participants with more environmentally-friendly starting solutions, customized their TV with lower carbon footprints (M_Default1 $=1042.23 \mathrm{~kg} \mathrm{CO} \mathrm{CO}_{2} \mathrm{e}, \mathrm{M} \_$Default2 $=1002.12 \mathrm{~kg} \mathrm{CO}$, M_Default3 $\left.=877.67 \mathrm{~kg} \mathrm{CO}_{2} \mathrm{e}, \mathrm{F}=9.665, \mathrm{p}<0.001\right)$. We used Levene's test of equality of error variances to examine the null hypotheses (that the error variance of the dependent variable was equal across groups). The test result showed that the homogeneity assumption has not been violated $(\mathrm{F}=50.726, \mathrm{p}<0.001)$. A post-hoc test (Tukey HSD) revealed that differences between Treatment 1 and 2 were not significant. However, differences between Treatment 1 and 3 were significant at the $\mathrm{p}<0.001$ level, while differences between Treatment 2 and 3 were significant at the $\mathrm{p}<0.050$ level (see Table 6). Thus, $\mathrm{H} 2 \mathrm{a}$ is supported.

$\mathrm{H} 2 \mathrm{~b}$ demands that the satisfaction is not significantly affected by the default configuration, defining an important criterion for the application of green nudges in an MC context. Our manipulation check with ANOVA, shows that the respondents who were confronted with more sustainable default configurations expressed slightly lower product satisfaction on average (Treatment $1=5.73$, Treatment $2=5.47$, Treatment $3=5.40)$. However, the standard deviations within each treatment group are much higher than the deviations between the treatment groups $(F=0.082, p=0.378)$. As the Levene's test of equality of error variances revealed that the null hypothesis (that the error variance of the dependent variable is equal across groups) must be rejected on a $\mathrm{p}<0.01$ level, we used the Games-Howell post-hoc test to test for significant effect between the three treatment groups. No significant effect could be detected. The same applies to the relationship between default treatment and process satisfaction. ANOVA did not reveal any significant effect confirmed with GamesHowell post-hoc test (see Table 7). Hence, we can confirm H2b.

Finally, we conducted ANCOVA for the dependent variable carbon footprint in a first model, product satisfaction in a second model, and process satisfaction in a third model, with gender, age, qualification, income, PINV, CfSC, EwC, and residence as covariates. Again, we conducted a post-hoc (Bonferroni) test to learn more about the differences among the three treatment groups. Differences in the resulting carbon footprints between Treatment 1 and 3, as well as between Treatment 2 and 3 remained significant at the $\mathrm{p}<0.001$ level. Differences between the least sustainable starting solution and the medium sustainable starting solution were again not significant. Once again, no significant effects could be detected 
Table 7 Study 1. ANCOVA-test of between-subjects effects (on carbon footprint)

\begin{tabular}{|c|c|c|c|c|c|}
\hline & & df & $\mathrm{F}$ & Sig & $\begin{array}{l}\text { Partial Eta } \\
\text { squared }\end{array}$ \\
\hline Factor & Default & 2 & 8.506 & 0.000 & 0.148 \\
\hline \multirow[t]{16}{*}{ Covariates } & Gender & 1 & 0.435 & 0.511 & 0.004 \\
\hline & Age & 1 & 0.124 & 0.725 & 0.001 \\
\hline & Qualification & 1 & 0.011 & 0.916 & 0.000 \\
\hline & Income & 1 & 0.628 & 0.430 & 0.006 \\
\hline & Residence (Germany) & 1 & 0.134 & 0.715 & 0.001 \\
\hline & Residence (Switzerland) & 1 & 0.553 & 0.459 & 0.006 \\
\hline & Residence (Turkey) & 1 & 0.081 & 0.776 & 0.001 \\
\hline & Residence (Italy) & 1 & 0.720 & 0.398 & 0.007 \\
\hline & CfSC & 1 & 13.291 & 0.000 & 0.119 \\
\hline & PINV & 1 & 0.408 & 0.525 & 0.004 \\
\hline & EwC & 1 & 0.072 & 0.790 & 0.001 \\
\hline & Intercept & 1 & 45.755 & 0.000 & 0.318 \\
\hline & Corrected model & 13 & 3.255 & 0.000 & 0.302 \\
\hline & Error & 98 & & & \\
\hline & Total & 112 & & & \\
\hline & Corrected total & 111 & & & \\
\hline
\end{tabular}

$\mathrm{N}=112, \mathrm{R}^{2}=0.302$ (Adjusted $\mathrm{R}$ Squared $=0.209$ )

regarding the influence of sustainable defaults on process and product satisfaction. Hence, the inclusion of covariates did not change the results regarding our assumptions of $\mathrm{H} 2 \mathrm{a}$ and $\mathrm{H} 2 \mathrm{~b}$.

With ANCOVA, we also tested between-subject effects of other covariates. According to H1, we assumed that higher CfSC significantly lowers the environmental impact of the final customized product. In our results, we find support for H1. The results show that the carbon footprint of the final product configuration is significantly influenced by the individual CfSC. Participants with a higher CfSC customized a more sustainable product with a significantly lower environmental impact on average than participants with lower CfSC $(\mathrm{F}=13.291, \mathrm{p}<0.001)$. Hence, we find support for our hypothesis that an MC setting encourages consumers to successfully transfer the individual attitude to action. All other covariates do not significantly influence the carbon footprint of the final configuration.

\section{Study 2: sustainability information test}

We designed Study 2 to primarily explore whether the provision of sustainability information reduces the environmental impact of the customized TVs. With Study 2, we tested Hypotheses 1, 3a, and 3b, using again a between-subject design. 


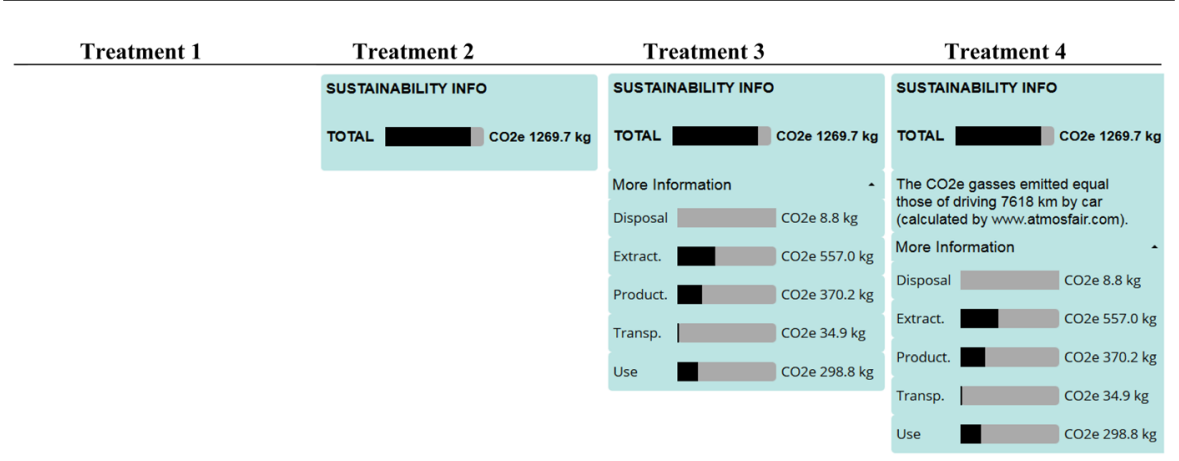

Fig. 2 Study 2. Sustainability information treatment groups

\subsection{Stimuli: manipulating the provision of sustainability information}

For testing the role of sustainability information for encouraging pro-environmental behavior, we developed four different configurator scenarios. In all four versions, the default option is the best-selling combination of components. In the first treatment (1), we deleted the entire sustainability overview panel. Hence, participants did not receive any information about the carbon footprint of their customized TV. The three following treatments $(2,3,4)$ differed in the degree of sustainability information that is provided during the configuration process. We assumed that beginning from zero sustainability information in Treatment 1 , the degree of perceived sustainability information increases from 2 to 3 to 4 . Treatment 4 contained the full sustainability panel described in the research design section above. For Treatment 3, we deleted the comparison information, which indicated the distance of a car ride equaling the carbon footprint of the customized TV. Treatment 2 in comparison to Treatment 3 only contained a single bar that visualized the total amount of $\mathrm{CO}_{2} \mathrm{e}$-emissions (carbon footprint) that would be emitted throughout the whole life cycle of the TV. Thus, we deleted the detailed split-up of the total emissions referring to the $\mathrm{CO}_{2} \mathrm{e}$-amounts emitted during different stages of the life cycle. An overview of all three manipulations is given in Fig. 2. Participants were randomly exposed to one of the four treatments.

\subsection{Participants and procedure}

According to the procedure described above, we cleaned the data of those participants who did not accomplish the required quality standards. 169 respondents assigned to one of the four sustainability information treatments remained. 111 respondents were male and 58 female. The age ranged between 18 and 64 years with an average of 27.49 years. Also, in Study 2, the median income of the sample was between 1500 and 2000 EUR. The median qualification of the sample was bachelor's degree. Most participants lived in Germany (94) followed by Switzerland (40), Italy (15) and Turkey (12), while eight participants lived in other countries. 


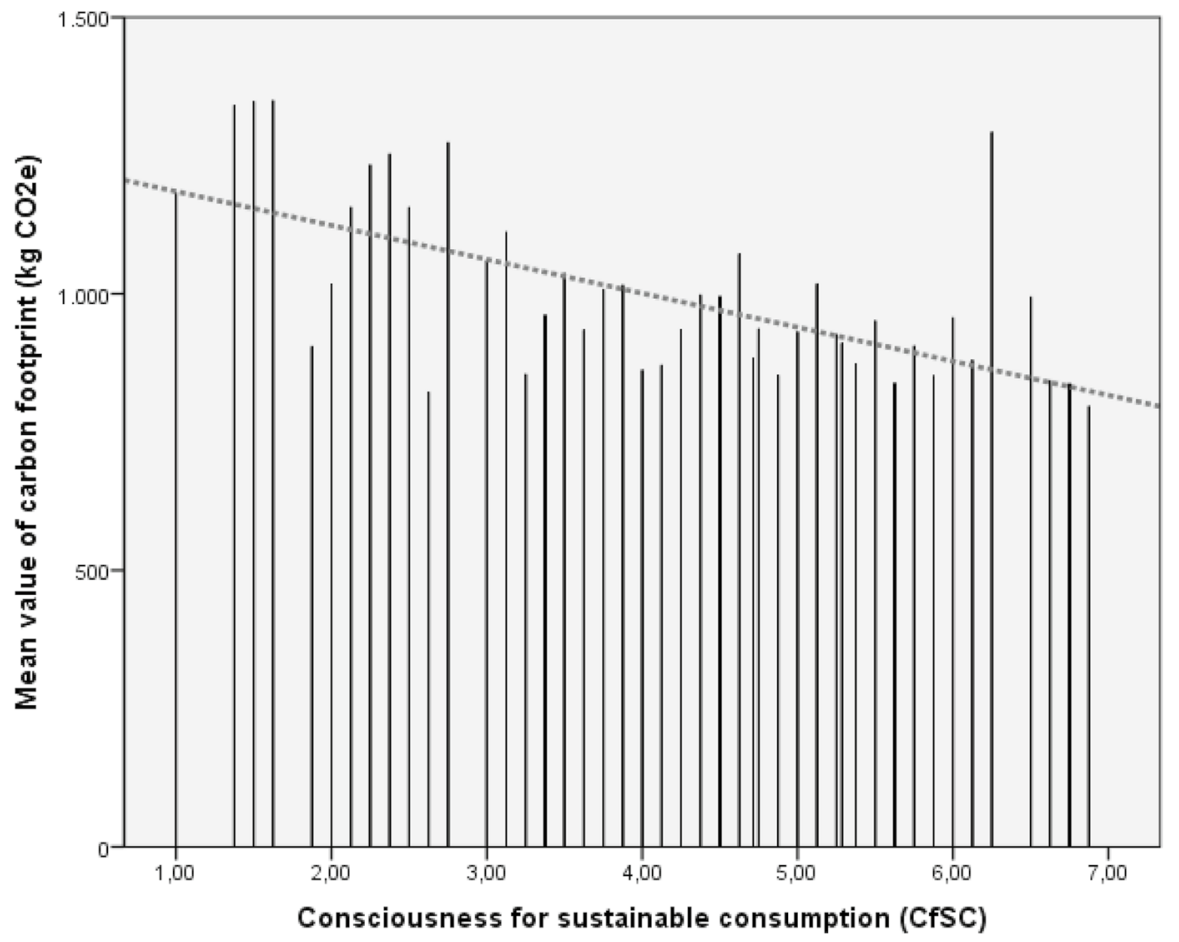

Fig. 3 Study 2. Relationship between consciousness for sustainable consumption and carbon footprint

\subsection{Results}

Similarly to Study 1, we tested between-subject effects to explore the effect of CfSC on the carbon footprint of the customized TV. Also, in Study 2, we find support for $\mathrm{H} 1$ in our results. Descriptive analysis shows that higher CfSC correspond to lower carbon footprints of the customized TVs on average (see Fig. 3). Analysis of covariance (ANCOVA with type III sum of squares) revealed that participants with higher CfSC customized more sustainable TVs with significantly lower environmental impacts on average than participants with lower CfSC $(\mathrm{F}=30.183, \mathrm{p}<0.001)$. The effect size is 0.160 (Partial Eta Squared). Hence, we can once again confirm that $\mathrm{MC}$ is suitable to encourage consumers to translate individual attitude to action.

To test H3, we performed a manipulation check to test whether the provision of sustainability was manipulated successfully. In $\mathrm{H} 3$, we claimed that the provision of more detailed sustainability information encourages consumers to act in a more pro-environmental way. The results of our study, however, show no support for this hypothesis. ANOVA revealed no significant effects between the four treatments $(\mathrm{F}=0.954, \mathrm{p}=0.416)$. Levene's test of equality of error variances showed no difference between the four treatments $(\mathrm{F}=2.742, \mathrm{p}=0.045)$. Thus, we used Tukey HSD post-hoc test to analyze effects between the treatments in more detail, revealing no significant manipulation effect between any of the four treatments. 
Table 8 Study 2. ANCOVA-test of between-subjects effects (on carbon footprint)

\begin{tabular}{|c|c|c|c|c|c|}
\hline & & df & $\mathrm{F}$ & Sig & $\begin{array}{l}\text { Partial Eta } \\
\text { squared }\end{array}$ \\
\hline Factor & Sustainability information & 3 & 0.891 & 0.447 & 0.017 \\
\hline \multirow[t]{16}{*}{ Covariates } & Gender & 1 & 1.272 & 0.261 & 0.008 \\
\hline & Age & 1 & 0.004 & 0.952 & 0.000 \\
\hline & Qualification & 1 & 1.446 & 0.231 & 0.009 \\
\hline & Income & 1 & 2.793 & 0.097 & 0.018 \\
\hline & Residence (Germany) & 1 & 0.594 & 0.442 & 0.004 \\
\hline & Residence (Switzerland) & 1 & 0.421 & 0.518 & 0.003 \\
\hline & Residence (Turkey) & 1 & 0.004 & 0.950 & 0.000 \\
\hline & Residence (Italy) & 1 & 1.759 & 0.187 & 0.011 \\
\hline & CfSC & 1 & 29.019 & 0.000 & 0.159 \\
\hline & PINV & 1 & 0.201 & 0.654 & 0.001 \\
\hline & EwC & 1 & 0.676 & 0.412 & 0.004 \\
\hline & Intercept & 1 & 79.572 & 0.000 & 0.341 \\
\hline & Corrected model & 14 & 3.770 & 0.000 & 0.255 \\
\hline & Error & 154 & & & \\
\hline & Total & 169 & & & \\
\hline & Corrected total & 168 & & & \\
\hline
\end{tabular}

$\mathrm{N}=169, \mathrm{R}^{2}=0.255$ (Adjusted $\mathrm{R}$ Squared $=0.188$ )

To test whether the manipulation check did not work due to the distinct influence of covariates within the treatment groups, we applied analysis of covariance (ANCOVA with type III sum of squares) using sustainability information as the independent factor and gender, age, qualification, income, PINV, CfSC, EwC, and residence as covariates (see Table 8). Also the analysis of covariance revealed that participants did not customize their TV in a more environmental-friendly way when confronted with more detailed information about the environmental impact $(\mathrm{F}=0.891, \mathrm{p}=0.447)$. Hence, we must reject our hypothesis. Our results manifest that the provision of information about the environmental impact did not nudge consumers towards more sustainable choices.

\section{Study 3: think-aloud test and interviews}

In a third study, we turned our attention to understanding the way consumers experience the customization process and how their decision-making looks like in detail. We mainly did this to understand why Study 2 did not produce the expected results for the manipulation of providing different levels of sustainability information. We, thus, focused on understanding how consumers perceived and used the sustainability information in the configurator, and how the provision could be improved. Based on Study 3, we sought to gain knowledge for modifying the TV product configurator for further consumer choice experiments. 


\subsection{Method}

For the purpose of the objectives of Study 3, we used the think-aloud method, a popular approach for usability testing (Nielsen 1994; Boren and Ramey 2000) combined with semi-structured interviews (Mayring 2000). In a think-aloud experiment, participants talk about their thoughts while solving a problem (van Someren et al. 1994). The participants are not interrupted by the researcher nor does the researcher ask questions. The method focusses entirely on the verbal expressions of the participants' thoughts without interpretations or explanations (van Someren et al. 1994). The think-aloud experiments were followed by problem-centered in-depth interviews with the participants. Moreover, for refining the configurator for further experiments, we conducted interviews with two experts, both working for a configurator development enterprise, to verify our results.

\subsection{Participant selection and procedure}

Ten participants took part in our study, three were female and seven male. On average, the participants were 29 years old, the youngest 23 and the oldest 63 years. The average duration of the experiment was 48:16 min. The shortest experiment was 32:22 and the longest 64:02 min. On average, the time spent in the configurator was 12:32. The shortest configuration time was 5:30 and the longest 23:00 min. Each participant received 15 EUR for her participation.

Before the experiment started, we welcomed the participant, and roughly introduced the topic and method. Moreover, we underlined anonymity and obtained agreement on voice and screen recordings. We recorded the screen using OBS Studio, and IOGraph for recording the cursor movement. To familiarize the participants with the methodology, we used a non-related exercise (estimation task) and a related exercise (configuring the first two steps of a customizable coffee purchase). As suggested by van Someren et al. (1994) for the actual think-aloud experiment, we constructed a short story. We did not answer questions during the test nor did we intervene besides requesting to continue talking after approximately $15 \mathrm{~s}$ of silence (van Someren et al. 1994; Ericsson 2006). After completing the configuration process (Treatment 4 of Study 2), we conducted problem-centered interviews with a pre-defined interview guide, asking the participant about their feelings during the configuration process, their perception of the configuration tool, about their objectives in the configuration process, and for their suggestions for improving the sustainability information.

\subsection{Results}

Eight participants noticed the sustainability information (IP1, IP2, IP3, IP4, IP5, IP7, IP9, IP10), and two did not (IP6, IP8). Most of the subjects looked at the information after regarding the price (IP1, IP2, IP4, IP7, IP10). Four participants considered the sustainability information at the beginning, one participant during, and 
three participants at the end of the customization process. All participants indicated that they found the provision of sustainability information useful or at least interesting. However, one participant felt entirely overwhelmed by the information, while other participants indicated that they might have needed more knowledge or additional information to fully understand the environmental impact assessment. IP2 for instance commented that he was missing comparison values to understand the scope of the carbon footprint measure for TVs. IP7 asked: "What does $934.4 \mathrm{~kg} \mathrm{CO}_{2} \mathrm{e}$ mean? Is this eco-friendly or not?"

IP1, IP4, and IP7 modified their configuration based on the carbon footprint of their customized TV after noticing the information. IP4 indicated that for him a low price was previously the most important objective. Nevertheless, he realized that for several options he could simultaneously obtain a low price and a low environmental impact. For the participant, reducing the carbon footprint "was a nice side effect." The degree to which the sustainability information changed the objectives of the participants and led to changes in the configuration widely differed between the participants. IP1, who only deselected the additional Bluetooth speaker afterwards, indicated that his "main goal was to get a nice television that does not leave an overly huge ecological footprint." In contrast, IP7 stated, "at the end, my thinking was actually solely influenced by the eco-friendliness aspect." According to IP4, the provision of sustainability information affected the importance of considering environmental implications along the product life cycle: "Well, earlier I honestly just considered the electricity at home and not the consumption or emission of $\mathrm{CO}_{2}$ during the production.[...] When you include both, the electricity consumption at home and the $\mathrm{CO}_{2}$-emissions during the production, for reducing consumption, then this category has overall definitely gained importance." Complementing the "I designed it myself" effect (Franke et al. 2010), participants perceived the sustainability information as part of translating their individual attitude into the product design (IP4, IP7).

Other participants who noticed the sustainability information, did not actively consider the sustainability information in their decision-making (IP2, IP3, IP5, IP9, IP10). An explanation could be that consumers not interested in the sustainability information simply blocked it, while those interested paid attention. IP3 did not choose any sustainable options, even though he actively noticed the sustainability information. He stated that his "focus was on a cheap television and all these $\mathrm{CO}_{2}$-neutral things would have cost me more, even though not that much more.[...] I paid attention to it, but it left me cold." This fits with the definition of a nudge implying that it can be dodged easily, without affecting the targeted user in a negative way (Thaler and Sunstein 2008).

Even though some users found the product configurator rather easy-to-use (IP1, IP2, IP3, IP4, IP7, IP9, IP10), others found the customization process difficult (IP5, IP6, IP8). Especially participants not considering the sustainability information reported that the configuration process itself was already quite demanding. Thus, a second explanation could be that the "limitations on the amount of information that we are able to receive, process, and remember" (Miller 1956, p. 95) were exceeded. In such a case, it is especially challenging for consumers to keep track of the rather uncommon sustainability information. Schwartz (2004) points out that people only 
perceive information until a certain threshold. Standard information on price, functionality and visual appearance are detected and processed, while any further information is not considered. This means that information exceeding the standard information must be especially arranged in a way that leaps to the eye.

Study 3 revealed that the rather technical presentation of the carbon footprint was perceived as very informative but without a clear environmental message, which prevents an easy translation into pro-environmental action. Moreover, the degree of gamification of the bar was limited. Thus, the degree to which consumers were encouraged to integrate sustainability in their decision-making was rather low. By collecting feedback from the participants of Study 3, we were able to derive several concrete recommendations for improving the design of the TV product configurator for further experiments. The participants suggested to improve the perception of sustainability information right from the beginning, highlighting the additional sustainability information before the configuration starts. Second, both participants and configurator experts recommended to shift up the position of the information (middle of the right side) above the price to increase the perception. Third, clear logos (eco-labels) instead of bars with detailed numbers could enhance perception and ensure comprehensibleness. If sticking to a bar, comparative values help to simultaneously improve the perception and the comprehensibleness, too. Fifth, the sustainability information could be highlighted in a more gamifying way (e.g., more creatively displaying the environmental impact changes according to consumer choices) so that consumers pay more attention to the information. Complementary to the perceived value of self-customization (Franke et al. 2010), consumers could customize products in a more sustainable way, while seeking configuration excitement and pleasure. Sixth, tips on how to make the configuration more sustainable should be available for users interested in sustainability during the configuration. The configurator experts recommended including such recommendations in an additional submenu to avoid overwhelming consumers. Finally, participants recommended highlighting the sustainability information with colors, signaling more clearly when a configuration is sustainable and when it is unsustainable.

\section{Study 4: sustainability information and visualization test}

The results of Study 3 inspired us to conduct a fourth study, in which we reconsidered and advanced Study 2 in a modified version. Moreover, we used a representative panel to increase the explanatory power of our study. Considering the insights generated in Study 3, we improved the representation of the sustainability information so that participants better perceive and comprehend the environmental impact during the configuration process. We used a visual representation similar to the "Nutri-Score", the front-of-pack nutrition label introduced by the French government in 2017 (Julia and Hercberg 2017) (Fig. 4). We assigned the carbon footprints of the TV to the five categories (green $\mathrm{A}=$ best to red $\mathrm{E}=$ worst) at even intervals (A until 919,6 kg CO 2 e, B until 1053,2 $\mathrm{kg} \mathrm{CO}_{2} \mathrm{e}, \mathrm{C}$ until 1186,8 $\mathrm{kg} \mathrm{CO}_{2} \mathrm{e}$, D until $1320,4 \mathrm{~kg} \mathrm{CO}_{2}$, and $\mathrm{E}$ for higher carbon footprints) (see Fig. 4). 
Fig. 4 Study 4. Sustainability visualization of carbon footprint based on Nutri-Score
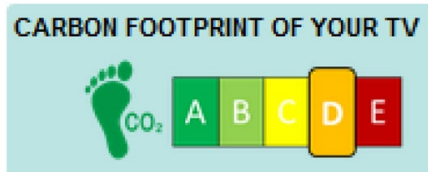

$1269.7 \mathrm{~kg} \mathrm{CO} 2 \mathrm{e}$

\subsection{Stimuli: manipulating the visualization of the sustainability information}

We decided to use a $2 \times 2$ design for testing the inclusion of sustainability visualization for encouraging pro-environmental behavior in direct comparison to a rather sober presentation of sustainability information. We developed four configurator scenarios. In all four versions, the default option remains the best-selling combination of components (Treatment 2 of Study 1). In the first treatment (1), we did not show any sustainability information. In Treatment 2 , we included our sustainability information for the overall carbon footprint and the respective life cycle phases. In Treatment 3, we showed the new visual representation based on the "Nutri-Score". In Treatment 4, we included both the new sustainability visualization based on the "Nutri-Score" and the detailed sustainability information for each phase of the product life cycle. An overview of all three manipulations is given in Fig. 5. Participants were randomly assigned to one of the four treatments.

\subsection{Participants and procedure}

We conducted Study 4 with consumers from Belgium, provided by an international market data provider. We decided to use Belgium because the national government had just recently introduced the Nutri-Score for food packaging (Johnston 2019), which ensured that participants intuitively understand the visualization. In total, 400 participants (200 male, 200 female) participated in our study. After conducting data cleaning similarly to the procedures described in Sect. 4.2, we used data from 189 men and 170 women. The average age of our participants is 39 years, the median income is between " $€ 2500$ and $€ 3000$ " and the median qualification is "bachelor's degree".

\subsection{Results}

To test $\mathrm{H} 3$ again, we performed manipulation checks to test whether the carbon footprint of the TV has been manipulated successfully. First, we used one-way ANOVA to reveal the influence of both sustainability information provision and Nutri-Score based sustainability visualization independently and jointly, using Treatments 1-4 as categorical groups. Comparing the means of the four treatments, we see that providing no information at all (Treatment 1) results in the highest average carbon footprint $(\mathrm{M}=1172.70)$, followed by providing only detailed sustainability information (Treatment 2 with $\mathrm{M}=1137.69$ ) and providing both information and visualization 


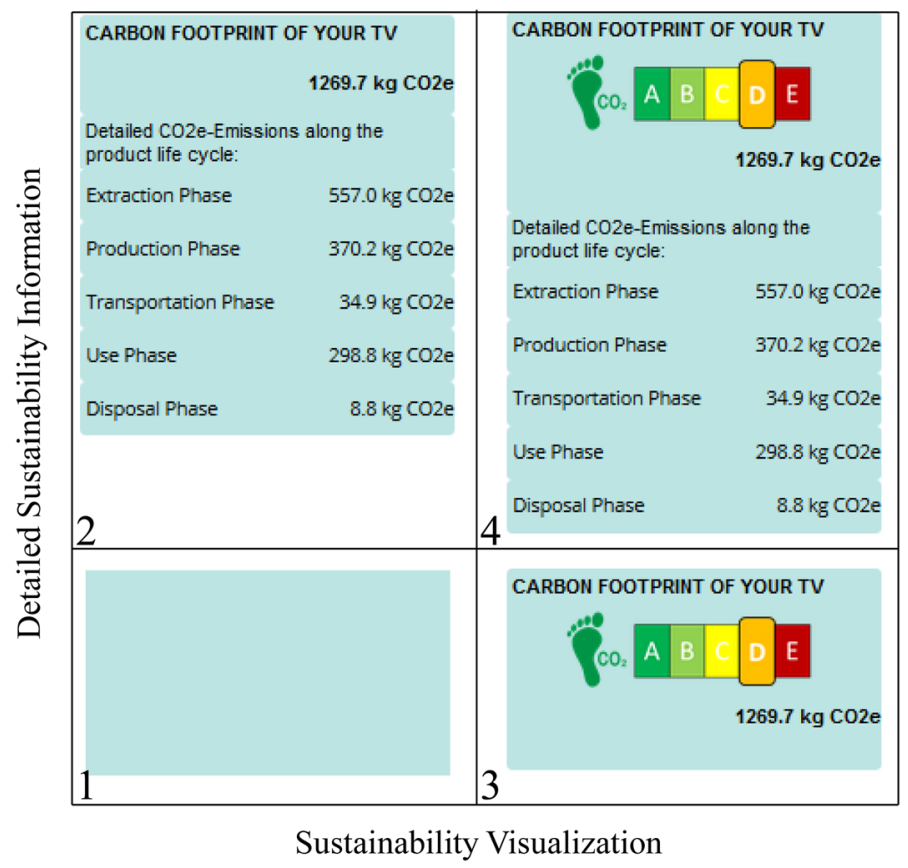

Fig. 5 Study 4. Sustainability information treatment groups

(Treatment 4 with $\mathrm{M}=1130.91$ ). We observe the lowest average carbon footprint of participants confronted with the sustainability visualization without additional detailed sustainability information (Treatment 3 with $M=1096.06$ ). ANOVA reveals only differences between the four treatments on a significance level of 90 percent $(\mathrm{F}=2.42, \mathrm{p}=0.066)$. Conducting post-hoc analysis of one-way ANOVA, we observe that the differences between the carbon footprint means of our treatment groups are only significant between Treatment 1 and 3, confirmed with Tukey HSD, Tukey-Kramer, and Fisher-Hayter pairwise comparisons (see Table 9). Thus, we can to confirm that the sustainability visualization influences consumer behavior, while detailed sustainability information does not.

Instead of looking at our four treatments as the independent variable, we conducted two-way ANOVA in a next step, using Sustainability Information and Sustainability Visualization as dummy variables, as well as the interaction between both. Again, we revealed no significant effect of including detailed sustainability information $(\mathrm{F}=0.000, \mathrm{p}=0.997)$, but a significant influence of including the more intuitive visualization $(\mathrm{F}=3.82, \mathrm{p}=0.052)$ on a $\mathrm{p}<0.1$ level. Two-way ANOVA revealed no significant interaction effect of sustainability information and sustainability visualization $(\mathrm{F}=2.68, \mathrm{p}=0.103)$ (see Table 10$)$.

In a final step, we also integrated covariates into our analysis. We added gender, age, qualification, income, PINV, CfSC and EwC to the independent factors sustainability information, sustainability visualization, and the interaction between both (see Table 11). Again, only Sustainability Visualization showed a significant effect 
Table 9 Study 4. Post-hoc Analysis of Main Effects of Sustainability Information and Visualization Treatments

\begin{tabular}{|c|c|c|c|c|c|c|c|}
\hline \multirow{2}{*}{$\begin{array}{l}\text { Dependent vari- } \\
\text { able }\end{array}$} & \multirow[t]{2}{*}{ Post-hoc test } & \multicolumn{6}{|c|}{ Post-hoc analysis } \\
\hline & & $\begin{array}{l}\text { Treat- } \\
\text { ment } 1 \\
\text { vs. } 2\end{array}$ & $\begin{array}{l}\text { Treatment } 1 \\
\text { vs. } 3\end{array}$ & $\begin{array}{l}\text { Treat- } \\
\text { ment } 1 \\
\text { vs. } 4\end{array}$ & $\begin{array}{l}\text { Treat- } \\
\text { ment } 2 \\
\text { vs. } 3\end{array}$ & $\begin{array}{l}\text { Treat- } \\
\text { ment } 2 \\
\text { vs. } 4\end{array}$ & $\begin{array}{l}\text { Treat- } \\
\text { ment } 3 \\
\text { vs. } 4\end{array}$ \\
\hline Carbon footprint & Tukey HSD & n.s & $\mathrm{p}<0.01$ & n.s & n.s & n.s & n.s \\
\hline Carbon footprint & Tukey-Kramer & n.s & $\mathrm{p}<0.05$ & n.s & n.s & n.s & n.s \\
\hline Carbon footprint & Fisher-Hayter & n.s & $\mathrm{p}<0.05$ & n.s & n.s & n.s & n.s \\
\hline
\end{tabular}

Table 10 Study 4. Two-way ANOVA-test of between-subjects effects (on carbon footprint)

\begin{tabular}{lrrrrl}
\hline Source & \multicolumn{1}{c}{ Partial SS } & Df & \multicolumn{1}{l}{ MS } & F & Prob $>$ F \\
\hline Model & $292,446.493$ & 3 & $97,482.165$ & 2.42 & 0.066 \\
Sustainability information & 0.576 & 1 & 0.576 & 0.00 & 0.997 \\
Sustainability visualization & $153,797.770$ & 1 & $153,797.770$ & 3.82 & 0.052 \\
Information x visualization & $107,829.378$ & 1 & $107,829.378$ & 2.68 & 0.103 \\
Residual & $14,257,181.100$ & 354 & $40,274.523$ & & \\
Total & $14,549,627.600$ & 357 & $40,755.259$ & & \\
\hline
\end{tabular}

$\mathrm{N}=358, \mathrm{R}^{2}=0.020$ (Adjusted R Squared $=0.012$ )

$(\mathrm{F}=8.44, \mathrm{p}<0.01)$, while neither Sustainability Information nor the interaction between both did. Moreover, our analysis revealed a significant influence of the gender of participants $\left(M \_m a l e=1158.31 \mathrm{~kg} \mathrm{CO}\right.$ and $\mathrm{M} \_$female $=1109.31 \mathrm{~kg} \mathrm{CO} \mathrm{CO}_{2} \mathrm{e}$, $\mathrm{F}=3.31, \mathrm{p}=0.070$ ), indicating a higher pro-environmental behavior of women on a $\mathrm{p}<0.1$ level. Finally, we again find support for $\mathrm{H} 1$ as CfSC has a significant influence on the carbon footprint of the customized TV. Thus, we can conclude that we partly confirm $\mathrm{H} 3$ and fully confirm $\mathrm{H} 1$.

\section{Discussion and Implications}

The aim of our studies was to investigate if and how the co-design process of MC could foster sustainable consumption. In Studies 1, 2 and 4, we were able to confirm that the co-design phase of MC generally enables consumers to transfer their attitude into action. The decomposition of choices-not deciding on the assortment, which TV to buy, but on an attribute level-makes it possible for consumers to not only design a TV which meets their needs in terms of (physical) fit, (hardware or software) functionality, and (esthetic) style, but also regarding sustainability concerns. Consumers with a high CfSC customize solutions that manifest their attitude into products with significantly lower environmental impacts. In our studies, we showed that consumers transfer their individual CfSC into action, confirming $\mathrm{H} 1$. At a conceptual level, these results help to bridge literature on MC and sustainable 
Table 11 Study 4. ANCOVA-test of between-subjects effects (carbon footprint)

\begin{tabular}{lrrrrr}
\hline Source & \multicolumn{1}{c}{ Partial SS } & Df & \multicolumn{1}{l}{ MS } & F & Prob $>$ F \\
\hline Model & $4,168,695.52$ & 73 & $57,105.42$ & 1.64 & 0.003 \\
Sustainability information & $10,168.55$ & 1 & $10,168.55$ & 0.29 & 0.590 \\
Sustainability visualization & $293,891.19$ & 1 & $293,891.19$ & 8.44 & 0.004 \\
Information x visualization & $45,721.15$ & 1 & $45,721.15$ & 1.31 & 0.253 \\
Gender & $115,212.32$ & 1 & $115,212.32$ & 3.31 & 0.070 \\
Age & $1,778,405.63$ & 50 & $35,568.11$ & 1.02 & 0.444 \\
Qualification & $374,649.56$ & 7 & $53,521.37$ & 1.54 & 0.156 \\
Income & $241,416.29$ & 9 & $26,824.03$ & 0.77 & 0.644 \\
PINV & 176.79 & 1 & 176.79 & 0.01 & 0.943 \\
CfSC & $1,393,722.40$ & 1 & $1,393,722.40$ & 40.01 & 0.000 \\
EwC & 3940.86 & 1 & 3940.86 & 0.11 & 0.737 \\
Residual & $7,976,823.69$ & 229 & $34,833.29$ & & \\
Total & $12,145,519.20$ & 302 & $40,216.95$ & & \\
\hline
\end{tabular}

$\mathrm{N}=303, \mathrm{R}^{2}=0.343$ (Adjusted $\mathrm{R}$ squared $=0.134$ )

consumption, introducing the notion that sustainability concerns matter as a source of individual consumer requirements.

Moreover, MC companies can actively nudge consumers towards more sustainable choices by modifying the design of product configurators, which guide consumers through the customization process. The results of our studies (partly) confirm that consumers can be encouraged to follow pro-environmental behavior in an MC setting. With the first study, we showed that the management of starting solutions does not only work for influencing to choose e.g., more expensive products, but also to customize more sustainable products (H2a). By looking also at the perceived product and process satisfaction, we were able to show that designing strong sustainable starting solutions does not undermine consumer satisfaction $(\mathrm{H} 2 \mathrm{~b})$. Contrarily to our assumptions, Study 2 could not demonstrate that highlighting the environmental impact of the customized TV in the configuration process nudges consumers to customize more sustainably. We did not find that the provision of sustainability information has a significant impact on the reduction of the carbon footprint of customizable TVs (H3). According to Weber (2006), it is generally difficult for consumers to react to abstract, time-delayed, unrelated-to-personal-experience threats from global warming. Making climate change more "vivid and concrete" has been described as a necessity for translating pro-environmental attitudes into pro-environmental behavior (Weber 2006). As revealed in Study 3, the way the sustainability information was presented in our experiment did not sufficiently create such a clear message resulting in a successful green nudge. With our fourth study, we showed that with a more comprehensive and more intuitive label the green nudge works successfully. Thus, our study demonstrates that visually enhanced information provision influences consumers to choose more sustainably. 


\subsection{Theoretical implications}

Our research makes several theoretical contributions. First, it bridges the gap between the domain of MC, choice architecture and sustainable consumption. Our findings complement prior work on green nudges that investigated means to facilitate the adoption of sustainable behavior and the consumption of sustainable products (Lehner et al. 2016; Kristensson et al. 2017; Schubert 2017). For the domain of $\mathrm{MC}$ research, we provide the first empirical study to investigate the theoretically assumed sustainability potential of the co-design phase of MC (Badurdeen and Liyanage 2011; Hankammer et al. 2016, 2018c). We were able to identify and confirm a sub-dimension for consumers to express their individual needs in their product co-design: CfSC. In our studies, we confirmed that the individual sustainability attitude significantly co-determines the environmental impact of the final customized product. Moreover, we complemented existing research on starting solutions for MC product configurators (Johnson et al. 2002; Levav et al. 2010; Hildebrand et al. 2014), confirming that defaults also work successfully for pre-configurations based on sustainability considerations. Especially with our fourth study, we advanced literature on influencing sustainable consumption based on ad-hoc sustainability information (Meise et al. 2014). The preliminary rejection of $\mathrm{H} 3$ and the subsequent qualitative post-hoc analysis revealed the challenges of understanding pro-environmental behavior through transparently communicating sustainability.

\subsection{Practical implications}

Apart from making a theoretical contribution by advancing the understanding of pro-environmental behavior in the context of customer co-design, our studies also have important practical implications for the design of toolkits that companies provide to enable consumers to co-design their own products. Taking into account that the vast majority of product configurators neither include any labeled sustainable options nor information about the sustainability of the attributes (Hankammer et al. 2016), our study is a pioneer in exploring how to integrate sustainability concerns into the co-design phase of MC. First, we introduced and used a product configurator for a TV, which was based on a detailed and realistic sustainability assessment of the solution space. We showed how the environmental impact assessment could be transferred into the design of sustainability communication panel in a product configurator. Second, we found in two studies that MC companies could use the co-design phase to enhance corporate sustainability in collaboration with their customers. Offering sustainable variants of attributes enables users to customize their products according to the individual importance ascribed to sustainability. Third, we not only showed that designing sustainable starting solutions lead to reduced carbon footprints of the final customized products, but also that consumer satisfaction is not jeopardized. For MC companies, sustainable defaults are thus promising and easyto-implement nudges. Finally, our Studies 2 and 3 revealed that providing consumers with an efficient but at the same time not overwhelming and predominant feedback 
about the sustainability impact of their customization is a challenging endeavor for MC companies, which requires further research.

\subsection{Limitations and directions for future research}

While the results of our study are mainly consistent with the theoretical background, our studies have a few limitations. First, the web-based TV configurator used in our study was not put to market yet, and thus our experiments were not real purchase situations. Nonetheless, all data and pictures used in the configurator are based on actual company information provided by a large European TV manufacturer. Hence, compared to similar choice experiments that study manipulations to observe sustainable buying behavior based on artificial product attributes in an artificial buying surrounding, our study relies on a more realistic setting. MC inherently builds upon the offer of several variants of different components (Dellaert and Stremersch 2005; Johnson et al. 2012). Hence, variations of the sustainable impacts of different variants of components did not have to be artificially invented but constituted a real customization situation.

In order to understand the user experience and the decision process of participants in more detail, we conducted a complementary qualitative study. This was especially necessary, because the different sustainability information treatments in Study 2 only marginally differed from each other. The complementary qualitative study confirmed our post-hoc assumption that the lack of significant robust results for the influence of sustainability information on the pro-environmental behavior could have resulted from our design of the manipulations. Our study revealed possibilities to improve the perception of the different levels. Some of the suggestions have resulted in an improved design of our manipulations in Study 4. For further experiments, we suggest continuing with our journey to particularly improve the message resulting from the inclusion of sustainability information. The passive display of changes within the carbon footprint could be replaced by more action-oriented and story-telling alternatives of sustainability information. Moreover, future research should focus on other indicators for reflecting the sustainability of products. This should include not only other environmental aspects such as repair-ability, but also social factors such as fair working conditions or exclusion of child labor.

In Study 1 and 2, we did not use a representative sample, but one that differed in multiple ways from Europe's population. A more representative and larger sample (as we used in Study 4) can increase the explanatory power of our model. We also only focused on one product category: consumer electronics. Furthermore, we restricted our analysis to the carbon footprint covering only one aspect of environmental sustainability. To ensure that the observed effects are generally valid, we propose to repeat the experiments with different products in different industries and with other environmental and most notably social sustainability indicators. Moreover, future research could complement our findings with manipulating other configurator design features than defaults and sustainability information. Specifically relevant are nudges that are based on the potential impacts of recommendations and peer-results (Franke et al. 2008; Hildebrand et al. 2013; Schubert 2017), and thus 
adding also Nudge type 2 to the analysis (Schubert 2017). The default analysis of Study 1 could be complemented by examining the design of the general structure and order of the presentation of components (Levav et al. 2010; Levin et al. 2002; Randall et al. 2005). Additionally, it is particularly interesting for MC companies to learn if the impact of sustainable default settings on product and process satisfaction differs for specific sub-groups. In our study, we proved that satisfaction is not significantly affected overall by introducing sustainable defaults. We recommend to transfer previous work of Hildebrand et al. (2014), which revealed that the fit of the starting solution with consumers' individual preferences significantly influences consumer satisfaction, to the topic of sustainable defaults. Moreover, it also would be interesting to check to which extent the brand of the product underlines the sustainability perception and trust in the provided information. Finally, we did not integrate re-configuration in our studies. Recent examples in the consumer electronics industry, such as Fairphone and Google's failed Project Ara (Hankammer et al. 2018a; Haucke 2018) emphasize that the initial point of sale is not the only co-design phase of MC relevant for a sustainability analysis. Thus, future research should also address the potential for nudges during re-configuration. Despite these limitations, we believe that our study provides important results in bridging between two large current consumer trends, customization and sustainability, and will inspire other researchers to investigate this important topic further.

Acknowledgements The research leading to these results has received funding from the Federal Ministry of Education and Research of Germany for the SMC-Excel project within the ECO-INNOVERA program (GA No. 033E006A). We thank all the project partners for valuable inputs throughout the entire research phase. Moreover, we acknowledge the feedback from participants of the 2018 Annual Meeting of the Academy of Management and the RWTH Aachen TIME research seminar on earlier versions of this paper. Finally, we would like to thank the editor and the reviewers for their suggestions for improvements throughout the review process.

Funding Open Access funding enabled and organized by Projekt DEAL.

Open Access This article is licensed under a Creative Commons Attribution 4.0 International License, which permits use, sharing, adaptation, distribution and reproduction in any medium or format, as long as you give appropriate credit to the original author(s) and the source, provide a link to the Creative Commons licence, and indicate if changes were made. The images or other third party material in this article are included in the article's Creative Commons licence, unless indicated otherwise in a credit line to the material. If material is not included in the article's Creative Commons licence and your intended use is not permitted by statutory regulation or exceeds the permitted use, you will need to obtain permission directly from the copyright holder. To view a copy of this licence, visit http://creativecommons.org/licen ses/by/4.0/.

\section{References}

Alriksson S, Öberg T (2008) Conjoint analysis for environmental evaluation. Environ Sci Pollut Res 15:244-257. https://doi.org/10.1065/espr2008.02.479

Auger P, Burke P, Devinney TM, Louviere JJ (2003) What will consumers pay for social product features? J Bus Ethics 42:281-304. https://doi.org/10.1023/A:1022212816261

Auger P, Devinney TM, Louviere JJ, Burke PF (2008) Do social product features have value to consumers? Int J Res Mark 25:183-191. https://doi.org/10.1016/j.ijresmar.2008.03.005 
Auger P, Devinney TM, Louviere JJ, Burke PF (2010) The importance of social product attributes in consumer purchasing decisions: a multi-country comparative study. Int Bus Rev 19:140-159. https:// doi.org/10.1016/j.ibusrev.2009.10.002

Badurdeen F, Liyanage JP (2011) Sustainable value co-creation through mass customisation: a framework. Int J Sustain Manuf 2:180-203. https://doi.org/10.1504/IJSM.2011.042151

Balderjahn I, Buerke A, Kirchgeorg M et al (2013) Consciousness for sustainable consumption: scale development and new insights in the economic dimension of consumers' sustainability. AMS Rev 3:181-192. https://doi.org/10.1007/s13162-013-0057-6

Boren MT, Ramey J (2000) Thinking aloud: reconciling theory and practice. IEEE Trans Prof Commun 43:261-278. https://doi.org/10.1109/47.867942

Brown CL, Krishna A (2004) The Skeptical shopper: a metacognitive account for the effects of default options on choice. J Consum Res 31:529-539. https://doi.org/10.1086/425087

Bughin J, Chui M, Manyika J (2013) Ten IT-enabled business trends for the decade ahead. McKinsey Q:1-13

Cerri J, Testa F, Rizzi F (2018) The more I care, the less I will listen to you: How information, environmental concern and ethical production influence consumers' attitudes and the purchasing of sustainable products. J Clean Prod 175:343-353. https://doi.org/10.1016/j.jclepro.2017.12.054

Chen J-X, Chen J (2017) Supply chain carbon footprinting and responsibility allocation under emission regulations. J Environ Manage 188:255-267. https://doi.org/10.1016/j.jenvman.2016.12.006

Cobbing M, Dowdall T (2014) Green Gadgets: designing the future - the path to greener electronics. Greenpeace International, Amsterdam

Davis SM (1987) Future perfect. Addison-Wesley, Reading

Dellaert BGC, Stremersch S (2005) Marketing mass-customized products: striking a balance between utility and complexity. J Mark Res 42:219-227. https://doi.org/10.1509/jmkr.42.2.219.62293

Dendler L (2014) Sustainability Meta Labelling: an effective measure to facilitate more sustainable consumption and production ? J Clean Prod 63:74-83. https://doi.org/10.1016/j.jclepro.2013.04.037

DeVellis RF (2012) Scale development: theory and applications. Sage Publications, Thousand Oaks

Elzinga R, Reike D, Negro SO, Boon WPC (2020) Consumer acceptance of circular business models. J Clean Prod 254:119988. https://doi.org/10.1016/j.jclepro.2020.119988

Ericsson KA (2006) Protocol analysis and expert thought: concurrent verbalizations of thinking during experts' performance on representative tasks. Cambridge Handb Expert Perform. https://doi. org/10.1017/CBO9780511816796.013

Farjam M, Nikolaychuk O, Bravo G (2019) Experimental evidence of an environmental attitude-behavior gap in high-cost situations. Ecol Econ 166:106434. https://doi.org/10.1016/j.ecolecon.2019.106434

Firat AF (1991) The consumer in postmodernity. Adv Consum Res 18:70-76

Fischer D, Stanszus L, Geiger S et al (2017) Mindfulness and sustainable consumption: a systematic literature review of research approaches and findings. J Clean Prod 162:544-558

Forza C, Salvador F (2006) Product information management for mass customization. Palgrave Macmillan, New York

Franke N, Hader C (2014) Mass or only "Niche Customization"? Why we should interpret configuration toolkits as learning instruments. J Prod Innov Manag 31:1214-1234. https://doi.org/10.1111/ jpim. 12137

Franke N, Piller FT (2003) Key research issues in user interaction with user toolkits in a mass customisation system. Int J Technol Manag 26:578-599. https://doi.org/10.1504/IJTM.2003.003424

Franke N, Piller F (2004) Value creation by toolkits for user innovation and design: the case of the watch market. J Prod Innov Manag 21:401-415. https://doi.org/10.1111/j.0737-6782.2004.00094.x

Franke N, Keinz P, Schreier M (2008) Complementing mass customization toolkits with user communities: How peer input improves customer self-design. J Prod Innov Manag 25:546-559. https://doi. org/10.1111/j.1540-5885.2008.00321.x

Franke N, Keinz P, Steger CJ (2009) Testing the value of customization: When do customers really prefer products tailored to their preferences? J Mark 73:103-121. https://doi.org/10.1509/jmkg.73.5.103

Franke N, Schreier M, Kaiser U (2010) The "I Designed It Myself" effect in mass customization. Manage Sci 56:125-140. https://doi.org/10.1287/mnsc.1090.1077

Fuchs DA, Lorek S (2005) Sustainable consumption governance: a history of promises and failures. J Consum Policy 28:261-288. https://doi.org/10.1007/s10603-005-8490-z

Gembarski PC, Lachmayer R (2017) Designing customer co-creation: business models and co-design activities. Int J Ind Eng Manag 8:121-130 
Gembarski PC, Schoormann T, Schreiber D et al (2018) Effects of mass customization on sustainability: a literature-based analysis. In: Hankammer S, Nielsen K, Piller FT et al (eds) Customization 4.0: proceedings of the 9th world mass customization and personalization conference (MCPC 2017), Aachen, Germany, November 20th-21st, 2017. Springer, Cham, pp 285-300

Goldstein BYDG, Eric J, Herrmann A (2008) Nudge your customers toward better choices. Harv Bus Rev 86:99-105

Grafmüller LK, Hankammer S, Hönigsberg S, Wache H (2018) Developing complex, mass-customized products in SME networks: perspectives from co-creation, solution space development, and information system design. Int J Ind Eng Manag 9:215-227. https://doi.org/10.24867/IJIEM $-2018-4-215$

Hankammer S, Hora M, Canetta L, Sel SK (2016) User-interface design for individualization services to enhance sustainable consumption and production. Procedia CIRP 47:448-453. https://doi. org/10.1016/j.procir.2016.03.077

Hankammer S, Kleer R (2018) Degrowth and collaborative value creation: reflections on concepts and technologies. J Clean Prod 197:1711-1718. https://doi.org/10.1016/j.jclepro.2017.03.046

Hankammer S, Jiang R, Kleer R, Schymanietz M (2018a) Are modular and customizable smartphones the future, or doomed to fail? A case study on the introduction of sustainable consumer electronics. CIRP J Manuf Sci Technol. https://doi.org/10.1016/j.cirpj.2017.11.001

Hankammer S, Nielsen K, Piller FT et al (2018b) Customization 4.0. Springer, Berlin

Hankammer S, Weber AM, Canetta L, et al (2018c) A sustainability based optimization model for starting solutions in toolkits for mass customization. In: 2017 International Conference on Engineering, Technology and Innovation (ICE/ITMC). IEEE, Funchal, pp 407-416

Hankammer S, Brenk S, Fabry H et al (2019) Towards circular business models: identifying consumer needs based on the jobs-to-be-done theory. J Clean Prod 231:341-358. https://doi.org/10.1016/j. jclepro.2019.05.165

Hankammer S, Antons D, Kleer R, Piller FT (2020) Taking stock of customization research: a computational review and interdisciplinary research agenda. SSRN Electron J. https://doi.org/10.2139/ ssrn.3632997

Hansen EG, Grosse-Dunker F, Reichwald R (2009) Sustainability innovation cube-a framework to evaluate sustainability-oriented innovations. Int J Innov Manag 13:683-713. https://doi. org/10.1142/S1363919609002479

Haucke FV (2018) Smartphone-enabled social change: Evidence from the Fairphone case? J Clean Prod 197:1719-1730. https://doi.org/10.1016/j.jclepro.2017.07.014

Haward MF, Murphy RO, Lorenz JM (2012) Default options and neonatal resuscitation decisions. J Med Ethics 38:713-718. https://doi.org/10.1136/medethics-2011-100182

Hertwich EG (2005) Life cycle approaches to sustainable consumption: a critical review. Environ Sci Technol 39:4673-4684

Hildebrand C, Häubl G, Herrmann A, Landwehr JR (2013) When social media can be bad for you: community feedback stifles consumer creativity and reduces satisfaction with self-designed products. Inf Syst Res 24:13-29. https://doi.org/10.1287/isre.1120.0455

Hildebrand C, Häubl G, Herrmann A (2014) Product customization via starting solutions. J Mark Res 51:707-725. https://doi.org/10.1509/jmr.13.0437

Honneth A (2004) Organized self-realization. Eur J Soc Theory 7:463-478. https://doi. org/10.1177/1368431004046703

Hora M, Hankammer S, Canetta L et al (2016) Designing business models for sustainable mass customization: a framework proposal. Int J Ind Eng Manag 7:118-125

Huffman C, Kahn BE (1998) Variety for sale: mass customization or mass confusion? J Retail 74:491-513

Jacobs K, Petersen L, Hörisch J, Battenfeld D (2018) Green thinking but thoughtless buying? An empirical extension of the value-attitude-behaviour hierarchy in sustainable clothing. J Clean Prod 203:1155-1169. https://doi.org/10.1016/j.jclepro.2018.07.320

Jin L, He Y, Song H (2012) Service customization: To upgrade or to downgrade? An investigation of how option framing affects tourists' choice of package-tour services. Tour Manag 33:266-275. https://doi.org/10.1016/j.tourman.2011.03.005

Johnson EJ, Goldstein D (2003) Do defaults save lives? Science (80-) 302:1338-1339. https://doi. org/10.1126/science.1091721

Johnson EJ, Bellman S, Lohse GL (2002) Defaults, framing and privacy: Why opting in-opting out. Mark Lett 13:5-15. https://doi.org/10.1023/A:1015044207315 
Johnson EJ, Shu SB, Dellaert BGC et al (2012) Beyond nudges: tools of a choice architecture. Mark Lett 23:487-504. https://doi.org/10.1007/s11002-012-9186-1

Johnston J (2019) The Nutri-Score system takes off in Belgium. The Brussels Times. https://www. brusselstimes.com/brussels/55086/the-nutri-scoresystem-officially-arrives-in-belgium

Julia C, Hercberg S (2017) Development of a new front-of-pack nutrition label in France: the fivecolour Nutri-Score. Public Heal Panor 3:712-725

Kahneman D, Knetsch JL, Thaler RH (1990) Experimental tests of the endowment effect and the Coase theorem. J Polit Econ 98:1325-1348. https://doi.org/10.1086/261737

Kalamas M, Cleveland M, Laroche M (2014) Pro-environmental behaviors for thee but not for me: green giants, green gods, and external environmental locus of control. J Bus Res 67:12-22. https://doi.org/10.1016/j.jbusres.2013.03.007

Kalana JA (2010) Electrical and electronic waste management practice by households in Shah Alam, Selangor, Malaysia. Int J Environ Sci 1:132-144. https://doi.org/10.6088/ijes.00102010003

Klintmann M (2012) Citizen-consumers and evolution: reducing environmental harm through our social motivation. Palgrave Macmillan, London

Kohtala C (2015) Addressing sustainability in research on distributed production: an integrated literature review. J Clean Prod 106:654-668

Kollmuss A, Agyeman J (2002) Mind the gap: Why do people behave environmentally and what are the barriers to pro-environmental behaviour. Environ Educ Res 8:239-260. https://doi. org/10.1080/1350462022014540

Kotler P (1986) The Prosumer Movement. A New Challenge for Marketers. Adv Consum Res 13:510-513

Kristensson P, Wästlund E, Söderlund M (2017) Influencing consumers to choose environment friendly offerings: evidence from field experiments. J Bus Res 76:89-97. https://doi. org/10.1016/j.jbusres.2017.03.003

Lehner M, Mont O, Heiskanen E (2016) Nudging-a promising tool for sustainable consumption behaviour? J Clean Prod 134:166-177. https://doi.org/10.1016/J.JCLEPRO.2015.11.086

Levav J, Heitmann M, Herrmann A, Iyengar SS (2010) Order in product customization decisions: evidence from field experiments. J Polit Econ 118:274-299. https://doi.org/10.1086/652463

Levin IP, Schreiber J, Lauriola M, Gaeth GJ (2002) A tale of two pizzas: building up from a basic product versus scaling down from a fully-loaded. Mark Lett 13:335-344. https://doi.org/10.1023/A:10203 70516638

Liu Y, Qu Y, Lei Z, Jia H (2017) Understanding the evolution of sustainable consumption research. Sustain Dev 25:414-430. https://doi.org/10.1002/sd.1671

Lorek S, Spangenberg JH (2014) Sustainable consumption within a sustainable economyC-C-beyond green growth and green economies. J Clean Prod 63:33-44. https://doi.org/10.1016/j.jclep ro.2013.08.045

Maity M, Dass M (2014) Consumer decision-making across modern and traditional channels: e-commerce, m-commerce, in-store. Decis Support Syst 61:34-46. https://doi.org/10.1016/j. dss.2014.01.008

Mayring P (2000) Qualitative content analysis. Forum Qual Soc Res 1:1-10. https://doi.org/10.111 1/j.1365-2648.2007.04569.x

Meise JN, Rudolph T, Kenning P, Phillips DM (2014) Feed them facts: value perceptions and consumer use of sustainability-related product information. J Retail Consum Serv 21:510-519. https://doi. org/10.1016/j.jretconser.2014.03.013

Miller GA (1956) The magical number seven, plus or minus two: some limits on our capacity for processing information. Psychol Rev 63:81-97. https://doi.org/10.1037/h0043158

Mont O (2004) Institutionalisation of sustainable consumption patterns based on shared use. Ecol Econ 50:135-153. https://doi.org/10.1016/j.ecolecon.2004.03.030

Nielsen J (1994) Estimating the number of subjects needed for a thinking aloud test. Int J Hum - Comput Stud 41:385-397. https://doi.org/10.1006/ijhc.1994.1065

Ofstad S, Westly L, Bratelli T (1994) Symposium: Sustainable Consumption. Norwegian Ministry for the Environment, Oslo

O'Rourke D, Ringer A (2015) The impact of sustainability information on consumer decision making. J Ind Ecol 20:882-892. https://doi.org/10.1016/j.socscimed.2013.05.029

Osorio J, Romero D, Betancur M, Molina A (2014) Design for sustainable mass-customization: design guidelines for sustainable mass-customized products. In: 2014 International Conference on 
Engineering, Technology and Innovation: Engineering Responsible Innovation in Products and Services, ICE 2014

Park CW, Jun SY, MacInnis DJ (2000) Choosing what i want versus rejecting what i do not want: an application of decision framing to product option choice decisions. J Mark Res 37:187-202. https ://doi.org/10.1509/jmkr.37.2.187.18731

Piller FT (2004) Mass customization: reflections on the state of the concept. Int J Flex Manuf Syst 16:313-334. https://doi.org/10.1007/s10696-005-5170-x

Piller FT, Tseng MM (2010) A mass of customizers: the wordpress software ecosystem. Handb Res Mass Cust Pers Strategy. https://doi.org/10.1007/978-3-663-08187-6

Piller FT, Walcher D (2006) Toolkits for idea competitions: a novel method to integrate users in new product development. R\&D Manag 36:307-318. https://doi.org/10.1111/j.1467-9310.2006.00432 . $\mathrm{X}$

Piller FT, Moeslein K, Stotko CM (2004) Does mass customization pay? An economic approach to evaluate customer integration. Prod Plan Control 15:435-444. https://doi.org/10.1080/0953728042 000238773

Pine JB (1993) Mass customization: the new frontier in business competition. Harvard Business School Press, Boston

Pourabdollahian G, Steiner F, Rasmussen OH, Hankammer S (2014) A Contribution toward a research Agenda: identifying impact factors of mass customization on environmental sustainability. Int J Ind Eng Manag 5:169-178

Randall T, Terwiesch C, Ulrich KT (2005) Principles for user design of customized products. Calif Manage Rev 47:68-85. https://doi.org/10.2307/41166317

Rex E, Baumann H (2007) Beyond ecolabels: what green marketing can learn from conventional marketing. J Clean Prod 15:567-576. https://doi.org/10.1016/j.jclepro.2006.05.013

Rhein S, Schmid M (2020) Consumers' awareness of plastic packaging: more than just environmental concerns. Resour Conserv Recycl 162:105063. https://doi.org/10.1016/j.resconrec.2020.105063

Rockström J, Steffen WL, Noone K et al (2009) Planetary boundaries: exploring the safe operating space for humanity. Ecol Soc. https://doi.org/10.5751/ES-03180-140232

Salvador F, De Holan PM, Piller F (2009) Cracking the code of mass customization. MIT Sloan Manag Rev 50:71-78

Sammer K, Wüstenhagen R (2006) The influence of eco-labelling on consumer behaviour - results of a discrete choice analysis for washing machines. Bus Strateg Environ 199:185-199. https://doi. org/10.1002/bse.522

Schäufele I, Hamm U (2018) Organic wine purchase behaviour in Germany: exploring the attitude-behaviour-gap with data from a household panel. Food Qual Prefer 63:1-11. https://doi.org/10.1016/j. foodqual.2017.07.010

Schubert C (2017) Green nudges: Do they work? Are they ethical? Ecol Econ 132:329-342. https://doi. org/10.1016/J.ECOLECON.2016.11.009

Schwartz B (2004) The paradox of choice: Why more is less. HarperCollins, New York

Sthiannopkao S, Hung M (2013) Handling e-waste in developed and developing countries: initiatives, practices, and consequences. Sci Total Environ 463:1147-1153. https://doi.org/10.1016/j.scito tenv.2012.06.088

Sundarakani B, De Souza R, Goh M et al (2010) Modeling carbon footprints across the supply chain. Int J Prod Econ 128:43-50. https://doi.org/10.1016/j.ijpe.2010.01.018

Thaler R, Sunstein CR (2003) Libertarian Paternalism. Am Econ Rev 93:175-179

Thaler RH, Sunstein CR (2008) Nudge: improving decisions about health, wealth, and happiness. Yale University Press, London

Tseng MM, Du X (1998) Design by customers for mass customization products. CIRP Ann - Manuf Technol 47:103-106. https://doi.org/10.1016/S0007-8506(07)62795-4

UNCED (1992) Agenda 21. In: United Nations Conference on Environment and Development. UNCED, Rio de Janerio

van Someren MW, Barnard YF, Sandberg J (1994) The think aloud method: a practical guide to modelling cognitive processes. Academic Press, Cambridge

von Hippel E, Katz R (2002) Shifting innovation to users via toolkits. Manage Sci 48:821-833. https:// doi.org/10.1287/mnsc.48.7.821.2817

Wang P, Liu Q, Qi Y (2014) Factors influencing sustainable consumption behaviors: a survey of the rural residents in China. J Clean Prod 63:152-165. https://doi.org/10.1016/j.jclepro.2013.05.007 
Weber EU (2006) Experience-based and description-based perceptions of long-term risk: why global warming does not scare us (yet). Clim Change 77:103-120. https://doi.org/10.1007/s1058 4-006-9060-3

Zaichkowsky JL (1985) Measuring the involvement construct. J Consum Res 12:341-352. https://doi. org/10.1086/208520

Zufall J, Norris S, Schaltegger S et al (2019) Business model patterns of sustainability pioneers-analyzing cases across the smartphone life cycle. J Clean Prod. https://doi.org/10.1016/j.jclep ro.2019.118651

Publisher's Note Springer Nature remains neutral with regard to jurisdictional claims in published maps and institutional affiliations. 